\title{
A Strong Wind Event on the Ross Ice Shelf, Antarctica: A Case Study of Scale Interactions
}

\author{
Sheeba NetTukandy Chenoli, John Turner, ${ }^{*}$ And Azizan Abu Samah \\ National Antarctic Research Centre, Institute of Postgraduate Studies, University of Malaya, \\ Kuala Lumpur, Malaysia
}

(Manuscript received 29 December 2014, in final form 16 July 2015)

\begin{abstract}
In situ observations, satellite imagery, numerical weather prediction, and reanalysis fields are used to investigate the synoptic and mesoscale environment of a strong wind event (SWE) at McMurdo Station/Ross Island region on the Ross Ice Shelf, Antarctica, on 10 October 2003. The SWE occurred during the passage of a sequence of three mesoscale low pressure systems from the central Ross Ice Shelf to the southwest Ross Sea. A potential vorticity (PV) analysis showed that the lows drew air of continental origin down the glacial valleys of the Transantarctic Mountains and onto the ice shelf as a katabatic drainage flow. However, the analysis indicated that the air mass associated with the SWE was of recurved maritime origin drawn in by the second mesoscale low (L2). This air mass approached McMurdo Station from the south where interactions with the orography played a critical role. In the early stages of the event, when the wind speed was less than $10 \mathrm{~m} \mathrm{~s}^{-1}$, the air was deflected around the topographical features, such as Minna Bluff and Black and White Islands. As the pressure gradient increased, winds of more than $10 \mathrm{~m} \mathrm{~s}^{-1}$ crossed the orography and developed mountain waves along the lee slopes. When the Froude number became larger than 1, large-amplitude vertically propagating mountain waves developed over the McMurdo Station/Ross Island area, increasing the wind to $16 \mathrm{~m} \mathrm{~s}^{-1}$. The reanalysis fields did not resolve the mesoscale lows; however, the Antarctic Mesoscale Prediction System (AMPS) model was able to simulate important characteristics of the SWE such as the mesoscale low pressure system, flow around the topographical barrier, and the mountain wave.
\end{abstract}

\section{Introduction}

The northwest Ross Ice Shelf (Fig. 1) is the site of more logistical operations than in any other part of the Antarctic as a result of the presence of McMurdo Station, which is the primary aviation hub of the U.S. Antarctic Program (USAP) (Klein et al. 2008). In the vicinity of McMurdo Station (Fig. 1) there are three skiways/airfields: the Ice Runway, Williams Field, and Pegasus Field. These airfields in Antarctica support local field logistics as well as intercontinental flights to and from Christchurch, New Zealand. All the flights are sensitive to adverse weather conditions, but the flights

* Additional affiliation: British Antarctic Survey, Cambridge, United Kingdom.

Corresponding author address: Sheeba Nettukandy Chenoli, National Antarctic Research Centre, Institute of Postgraduate Studies, University of Malaya, 50603 Kuala Lumpur, Malaysia. E-mail: sheeba@um.edu.my from New Zealand have a point of no return, making it particularly important to have accurate weather forecasts for the runways.

Prediction of weather conditions on the Ross Ice Shelf (Fig. 1) presents a number of challenges. The area is affected by the many synoptic-scale weather systems that occur over the Ross Sea, with some of these depressions moving onto the ice shelf itself. There are also many mesoscale lows observed on the ice shelf and especially over the southwestern Ross Sea (Bromwich 1991). A strong wind event (SWE) at McMurdo Station is defined as an occasion when the wind speed is Beaufort scale 6 and above, which is $22 \mathrm{kt}$ or $11.3 \mathrm{~m} \mathrm{~s}^{-1}$ (Chenoli et al. 2012). Mesoscale lows over the Ross Sea have been examined in several studies (Carrasco and Bromwich 1994; Carrasco et al. 2003) and these studies showed that the lows generally had relatively low wind speeds associated with them, although stronger winds could occur. SWEs can cause major disruption to logistical operations and it is important to be able to predict such events. Some of these events can be caused by 


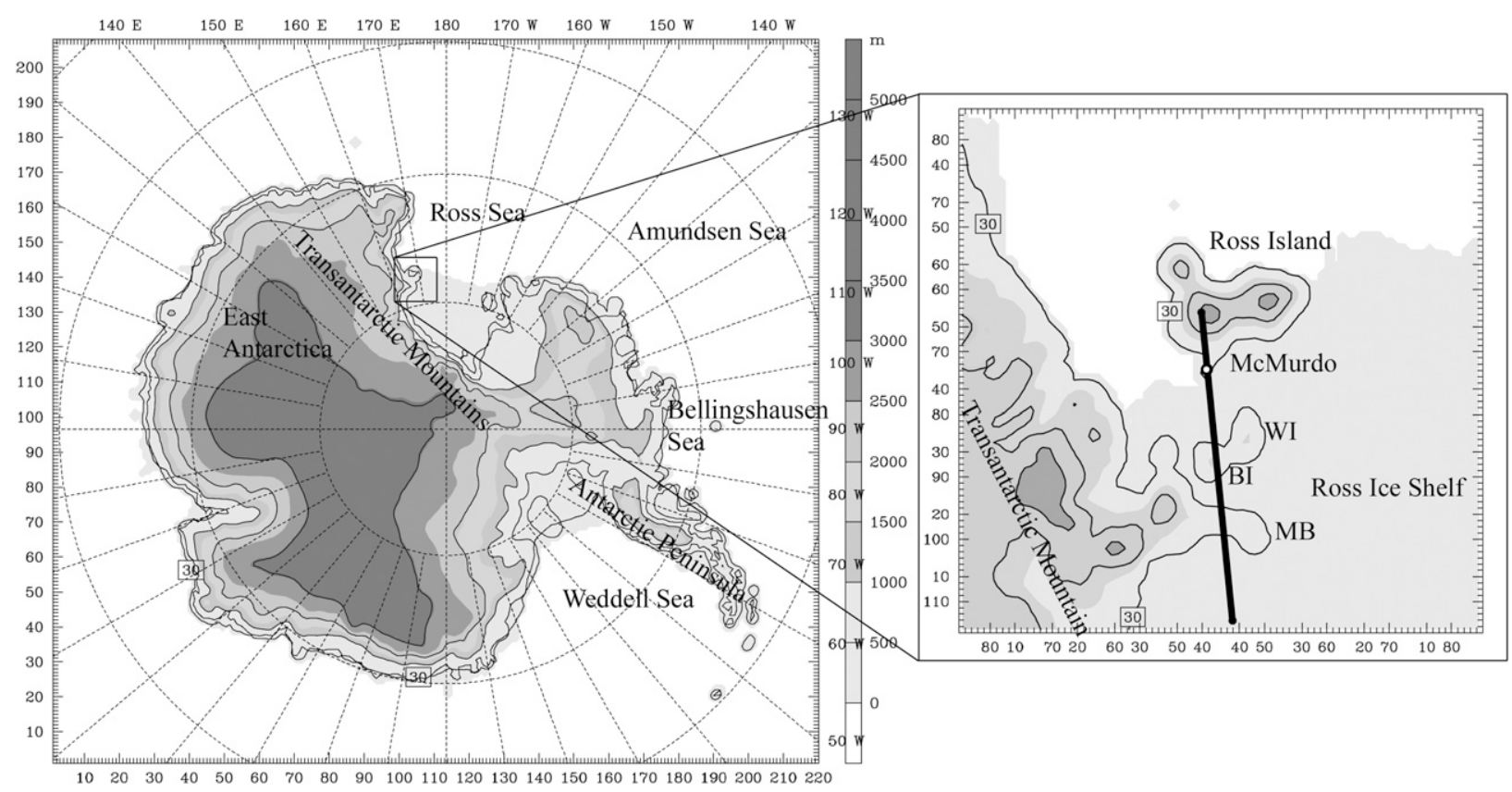

FIG. 1. Map of Antarctica with inset map of the Ross Ice Shelf area. In the inset figure, BI, WI, and MB stand for Black Island, White Island, and Minna Bluff respectively. The black line in the inset figure represents the location of the transect used in the study.

major synoptic lows in the Ross Sea/Ross Ice Shelf area, but mesoscale systems can also have strong winds associated with them. Strong katabatic winds are a significant feature along the coast of East Antarctica but are rarely experienced in the McMurdo Station area (Turner et al. 2009), although some continental air masses can affect the region. However, the barrier winds created by the flow along the Transantarctic Mountains are a major feature in McMurdo Station/Ross Island region (Seefeldt et al. 2007).

Case studies are very important in helping us to understand the synoptic background to SWEs and allowing us to assess the ability of numerical weather prediction (NWP) systems to correctly simulate their development and evolution. Steinhoff et al. (2008) investigated a severe storm that occurred in May 2004 in the McMurdo Station area using the Antarctic Mesoscale Prediction System (AMPS) model (Powers et al. 2012). This event occurred as a result of a deep synoptic-scale depression that tracked from the Amundsen Sea onto the Ross Ice Shelf with a maximum wind speed of $71.5 \mathrm{~m} \mathrm{~s}^{-1}$ recorded at McMurdo Station-the highest recorded for 12 years. In this paper we investigate an SWE that occurred on 10 October 2003 and that involved both synoptic and mesoscale low pressure systems on the Ross Ice Shelf. It illustrates the complex interactions between low pressure systems of different scales that can occur in the Antarctic. Such interactions are particularly difficult to simulate in NWP systems, yet are important for forecasting in areas such as the Ross Ice Shelf.

In section 2 we provide information on the various forms of data used in this study and describe the processing used. Section 3 presents an overview of the development of the broad-scale synoptic environment during the event. Section 4 discusses the details of airflow analysis and the involvement of katabatic wind and section 5 gives details of the wind flow over the northwest Ross Ice Shelf during the SWE and a discussion on the performance of AMPS in simulating the SWE. Section 6 concludes with a summary of the study.

\section{Data and methods}

This study was carried out using automatic weather station (AWS) observations, surface and upper-air radiosonde data from McMurdo Station, and Moderate Resolution Imaging Spectroradiometer (MODIS) satellite imagery. Reanalysis fields from the latest global atmospheric reanalysis produced by the European Centre for Medium-Range Weather Forecasts (ECMWF), ERA-Interim, were used to obtain the information on the broad-scale synoptic environment of the SWE. ERA-Interim analysis uses T255 spectral harmonic representation for basic dynamical fields and a reduced Gaussian grid N218 with approximately uniform horizontal spacing of $79 \mathrm{~km}$ (Dee et al. 2011). The data used in the analysis are the interpolated dataset to $0.125^{\circ}$ 
TABLE 1. A list of the UW-AWS systems used in this study.

\begin{tabular}{|c|c|c|c|c|}
\hline Data file name & Name of the station & Lat & Lon & $\begin{array}{l}\text { Station height } \\
\text { MSL (m) }\end{array}$ \\
\hline 089011003.r & Cape Bird (CBD) & $77.22^{\circ} \mathrm{S}$ & $166.44^{\circ} \mathrm{E}$ & 42 \\
\hline 089291003.r & Ferrell (FER) & $77.91^{\circ} \mathrm{S}$ & $170.82^{\circ} \mathrm{E}$ & 45 \\
\hline 089111003.r & Gill (GIL) & $79.99^{\circ} \mathrm{S}$ & $178.61^{\circ} \mathrm{W}$ & 25 \\
\hline 213601003.r & Laurie II (LR2) & $77.53^{\circ} \mathrm{S}$ & $170.81^{\circ} \mathrm{E}$ & 38 \\
\hline 089081003.r & Lettau (LET) & $82.52^{\circ} \mathrm{S}$ & $174.45^{\circ} \mathrm{W}$ & 30 \\
\hline 213621003.r & Linda (LDA) & $78.45^{\circ} \mathrm{S}$ & $168.39^{\circ} \mathrm{E}$ & 43 \\
\hline 089051003.r & Manuela (MLA) & $74.95^{\circ} \mathrm{S}$ & $163.69^{\circ} \mathrm{E}$ & 78 \\
\hline 089061003.r & Marble Point (MPT) & $77.44^{\circ} \mathrm{S}$ & $163.75^{\circ} \mathrm{E}$ & 108 \\
\hline 089341003.r & Marilyn (MLN) & $79.95^{\circ} \mathrm{S}$ & $165.13^{\circ} \mathrm{E}$ & 75 \\
\hline 089351003.r & Minna Bluff (MNB) & $78.55^{\circ} \mathrm{S}$ & $166.69^{\circ} \mathrm{E}$ & 895 \\
\hline 089131003.r & Schwerdtfeger (SWT) & $79.90^{\circ} \mathrm{S}$ & $169.97^{\circ} \mathrm{E}$ & 60 \\
\hline 089071003.r & Whitlock (WTL) & $76.14^{\circ} \mathrm{S}$ & $168.39^{\circ} \mathrm{E}$ & 275 \\
\hline 213641003.r & William Field (WFD) & $77.86^{\circ} \mathrm{S}$ & $167.02^{\circ} \mathrm{E}$ & 40 \\
\hline 089271003.r & Windless Bight (WDB) & $77.73^{\circ} \mathrm{S}$ & $167.70^{\circ} \mathrm{E}$ & 60 \\
\hline
\end{tabular}

from the native T255 horizontal using Meteorological Archival and Retrieval System (MARS). Surface meteorological observations are obtained from the University of Wisconsin (UW) automatic weather station program (Lazzara et al. 2012) to understand meteorological conditions as well as the synoptic background associated with SWE. Further details regarding UWAWSs used in this study can be found in Table 1. AWSs maintained by the Malaysian Antarctic Research Program (MARP) were used to understand the processes taking place during the SWE. The MARP maintains three AWS units (AWS1, AWS2, AWS3) in the vicinity of Scott Base; in this study, we have used the data from AWS1 $\left(77.90^{\circ} \mathrm{S}, 167.05^{\circ} \mathrm{E}\right)$ and AWS2 $\left(77.89^{\circ} \mathrm{S}\right.$, $\left.167.09^{\circ} \mathrm{E}\right)$. In this paper, these AWSs will be referred to as WF-AWS1 and WF-AWS2. The meteorological parameters recorded are pressure, temperature, relative humidity, and wind speed and direction. MODIS satellite images (processed and provided by Matthew Lazzara, Antarctic Meteorological Research Center) were used to identify and provide information on the track of major weather systems associated with the SWE and were valuable in comparing the observed position of the low pressure systems with the position simulated by AMPS as well as reanalysis. McMurdo Station releases a radiosonde at 0000 and 1200 UTC during the summer months, and nearly every day at 0000 UTC during the winter. However, during high wind periods radiosondes are rarely launched. The relatively dense network of AWSs at the northwest corner of the Ross Ice Shelf provides a good opportunity to construct hand-drawn surface charts to carry out a comprehensive study of the surface wind field. The hand-drawn charts are necessary to perform a detailed analysis as the dense network is restricted to the northwest part of the ice shelf and instances of missing data due to the possibility of AWS not operating in the harsh Antarctic environment. The hand-drawn surface charts utilized the available AWS data over the northwest Ross Ice Shelf between the latitudes $75^{\circ}-84^{\circ} \mathrm{S}$ and longitudes $120^{\circ} \mathrm{E}-160^{\circ} \mathrm{W}$. Figure 2 features the location of AWS stations used for the analysis and the locations of UW-AWS are given in Table 1. To overcome the limited observational data during the SWE, manual analyses were based on a

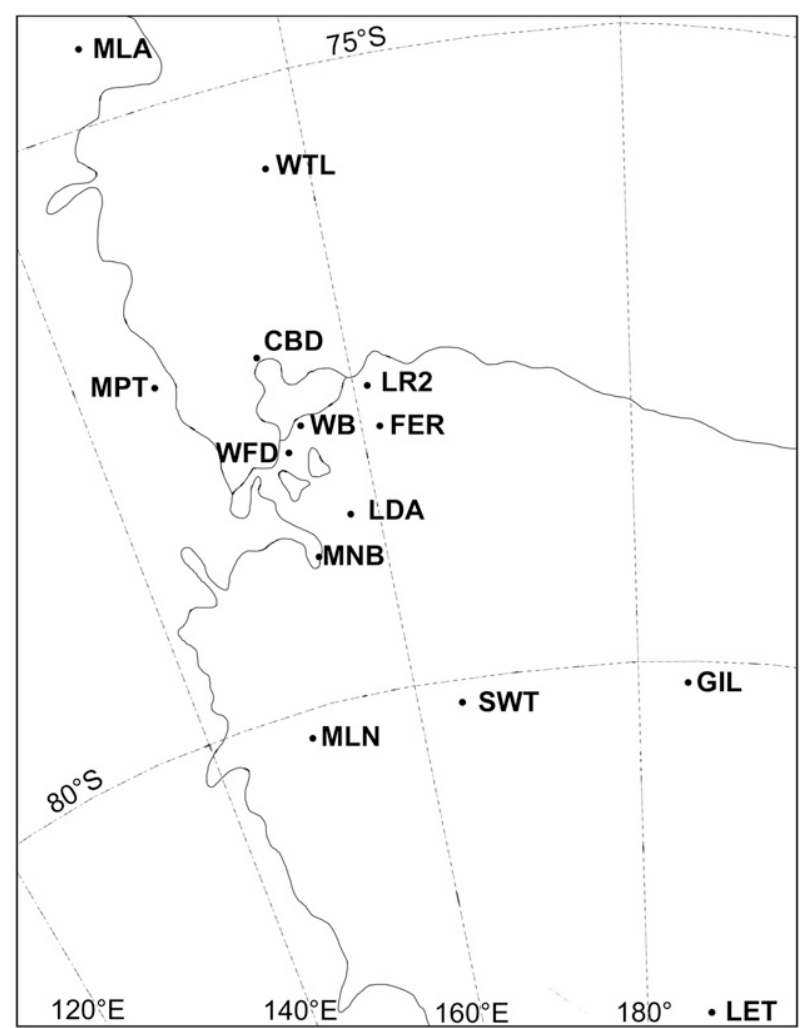

FIG. 2. Locations of AWS used for the manual mean sea level pressure analysis. 
combination of AWS observations and infrared structure of low pressure system from the satellite imageries.

Three-hourly surface analyses were hand-drawn for the period of the SWEs in order to get a clear picture of the tracks of the lows. For the preparation of the surface charts, all the station level pressure data were reduced to MSLP before the analysis using a hypsometric equation (Phillpot 1991). Some of the AWSs are excluded from the hand-drawn surface chart because of their close proximity to each other. Additional hourly analyses were carried out during the high wind period, when necessary. The analyses permitted the recognition of subsynoptic and mesoscale features associated with the SWEs that were not resolved in ERA-Interim reanalysis fields. Combined with the satellite images, the surface manual analysis helps to locate and track the low pressure systems. It also permitted us to track the systems when there were gaps in the satellite imageries or when the low pressure systems were not visible due to the cloud coverage. In addition, the satellite imageries showed that the evolution of the synoptic and mesoscale lows and their interactions were probably not simulated fully by the numerical models. This will be discussed in later sections.

Interaction of the surface flow over the Ross Ice Shelf with the topography in the vicinity of Ross Island is studied with the use of Froude number. The Froude number is a scaling parameter that can be used to determine whether an atmospheric flow will traverse a topographic barrier or be deflected around it. Interaction of airflow depends on the stability of the atmospheric layer as well as on the height of the terrain barrier. Brighton (1978), Hunt and Snyder (1980), and Snyder et al. (1985) used a similar approach to study the flow around obstacles. Earlier studies by O'Connor and Bromwich (1988), O'Connor et al. (1994), and Burk et al. (1999) also used a simple version of the Froude number equation to study the wind flow around the Ross Island. To understand the dynamics of the wind flow around the Ross Island area during high and low wind cases, Seefeldt et al. (2003) used the Froude number calculations with a study of the equations of motion.

The Froude number is defined as

$$
\mathrm{Fr}=U_{0}\left(g h \frac{\Delta \theta}{\theta}\right)^{-1 / 2},
$$

where $U_{0}$ is the wind speed, $g$ is the gravitational acceleration $\left(9.8 \mathrm{~m} \mathrm{~s}^{-2}\right), h$ is the height of the obstacle, $\Delta \theta$ is the difference in potential temperature between the surface and the top of the obstacle, and $\theta$ is the average potential temperature of the layer between the surface and the height of the obstacle. If $\mathrm{Fr}<1$, the static stability dominates over inertia therefore, the flow will not have sufficient kinetic energy to override the topography, whereas if $\mathrm{Fr}>1$ the flow will be able to override the barrier.

To supplement the limited availability of in situ data, the archive of NWP model forecasts from the AMPS was also used. AMPS is a mesoscale numerical weather prediction system, which is run at the Mesoscale and Microscale Meteorology (MMM) Laboratory of the National Center for Atmospheric Research (NCAR) in particular, to support the U.S. Antarctic Program and other international Antarctic activities (Powers et al. 2003, 2012). In the initial configuration AMPS employs the Polar MM5 (Bromwich et al. 2001; Cassano et al. 2001), which was replaced by the polar version of the Weather Research and Forecasting Model (Polar WRF) in 2006. The domain configuration of AMPS in the initial stages comprised a nested two-way interactive domain setup with grid horizontal spacing of 90 and $30 \mathrm{~km}$ and higher resolution of $10-$ and $3.3-\mathrm{km}$ grids. The vertical resolution reflects $31 \sigma$ levels between the ground and the model top at $50 \mathrm{hPa}$. The initial and boundary conditions of AMPS are obtained from National Centers for Environmental Prediction's (NCEP) Global Forecast System (GFS). Observational data in the Antarctic region such as reports from manned surface stations, surface AWSs, upper-air stations, and satellitederived cloud-track winds are also included in AMPS. The system also ingests sea ice data daily from the National Snow and Ice Data Center for initializing its fractional sea ice depiction. The archived AMPS output used for this study utilized mesoscale model Polar MM5, which in this paper will be referred to as AMPS output. The model output from the 30-, 10-, and 3.3-km horizontal resolution runs was used to investigate certain salient features of the SWE. AMPS produces forecasts twice daily, which are initialized at 0000 and 1200 UTC. For this study, forecasts from $12 \mathrm{~h}$ onward are used to provide sufficient time for the spinup of model fields. For AMPS $30-\mathrm{km}$ grid forecasts are available at $3-\mathrm{h}$ intervals and $3.3-\mathrm{km}$ forecasts at $1-\mathrm{h}$ intervals.

\section{Synoptic overview}

The event analysis was carried out using observational data from AWSs and the MODIS satellite as well as the ERA-Interim reanalysis fields. Three-hourly analyzed surface charts were also utilized to get a clear picture of the synoptic features of the SWE. In addition, numerical simulation results from the AMPS archive were also used to investigate the mechanisms involved. The SWE occurred during the passage of three mesoscale lows, L1, L2, and L3, across the northwestern Ross Ice Shelf to 


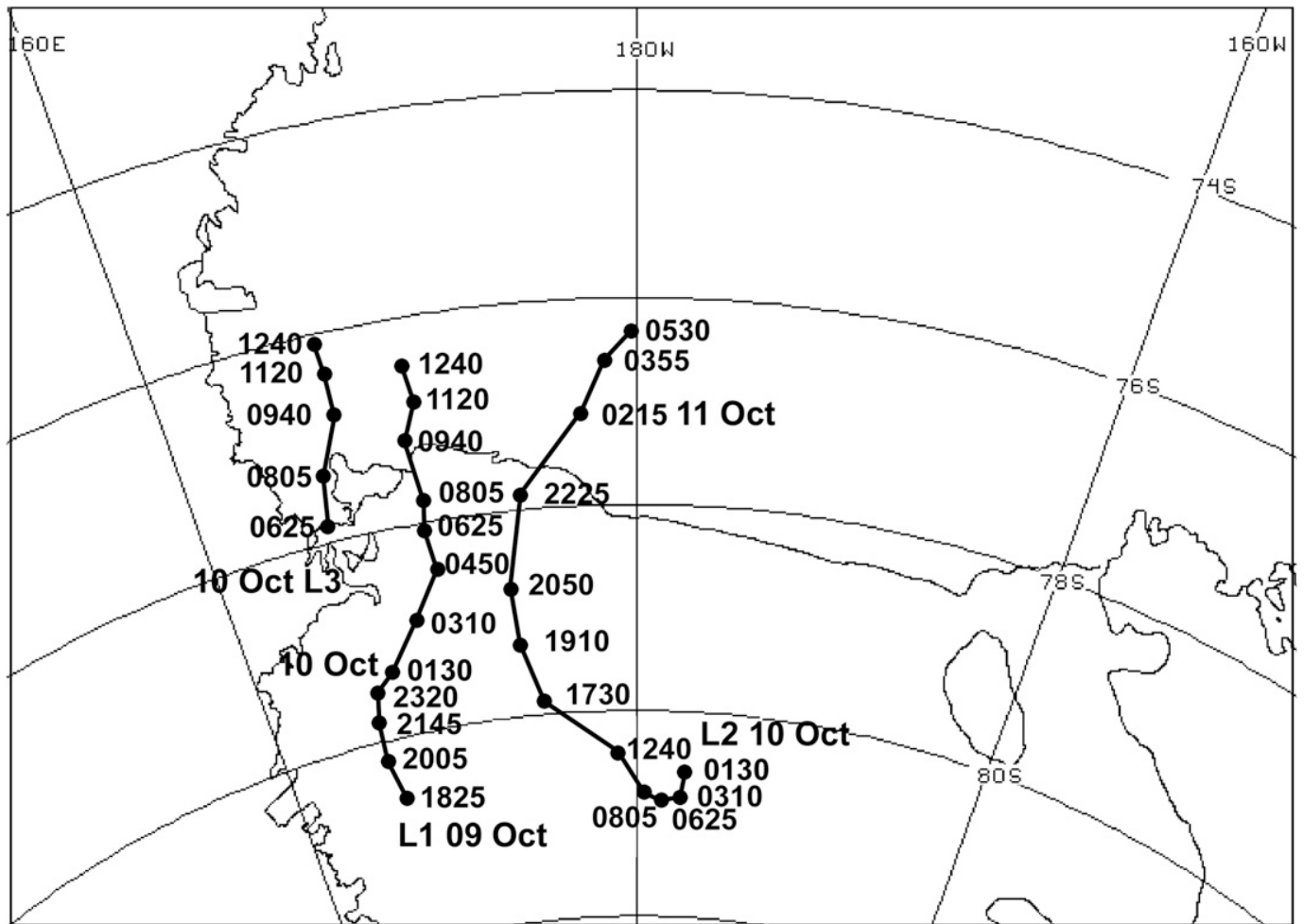

FIG. 3. Tracks of the low pressure systems L1, L2, and L3 from 1825 UTC 9 Oct to 0530 UTC 11 Oct 2003.

the southern Ross Sea. These lows are tracked using MODIS satellite images available from 1200 UTC 9 October to 0600 UTC 11 October 2003 (Fig. 3). The low L1 developed on the Ross Ice Shelf and first became detectable on the MODIS satellite imagery as an organized cloud mass at 1825 UTC 9 October 2003. The low L1 then tracked in a northward direction for the remaining $18 \mathrm{~h}$ to reach the northeast part of Ross Island at 1240 UTC 10 October. The satellite imagery at 0625 UTC (Fig. 4a) showed there was a distinct cloud band associated with the mesoscale low L1 $\left(77.8^{\circ} \mathrm{S}\right.$, $170^{\circ} \mathrm{E}$ ) and a larger system L2 southeast of L1 at around $81^{\circ} \mathrm{S}, 175^{\circ} \mathrm{W}$. The satellite imagery (at 0805 UTC) also showed a third mesoscale low L3 developing by 0625 UTC (Fig. 4a). However, its origins are difficult to determine as it evolved out of a disorganized mass of cloud over Ross Island. The ERA-Interim MSLP field at 0600 UTC 10 October (Fig. 5a) only had one large low pressure system on the Ross Ice Shelf and a trough of low pressure area north of Ross Island. The MSLP field did not resolve the three low pressure centers. In the reanalysis the low pressure center was at a more northerly position compared to the location on the satellite images at around $78^{\circ} \mathrm{S}, 180^{\circ}$, with a central pressure of $970 \mathrm{hPa}$. At this time (0600 UTC 10 October 2003) the manual analysis revealed two low pressure small-scale systems (L1 and L2) (Fig. 6a) and localized high pressure systems at Windless Bight (WB), south of Ross Island and south of Minna Bluff (Figs. 6b,c). The high pressure area south of Ross Island is a climatological feature on the Ross Island region, and its presence can be ascribed to the influences of the topography. When the southerly flow reaches a topographical barrier such as Ross Island, cold air piles up on the windward side as the flow is deflected around it. When the southerly wind flow is unable to override the topographical barriers, cold air piled up at the base of the topography, creating comparatively high pressure areas. This has been discussed in the work of Seefeldt et al. (2003), Monaghan et al. (2005), and Chenoli et al. (2012). The manual analysis has been carried out to confirm the existence and position of the mesoscale systems since the reanalysis field cannot resolve the mesoscale lows. The manual analysis was prepared based on the satellite imagery as well as AWS observations in order to address the issue of lack of in situ observations. However, even the manual analysis was unable to resolve the existence of transient small-scale low L3 because of the lack of data over the southwestern part of the Ross Sea (Figs. 6a-d). Based on the previous satellite image at 0300 UTC 10 October and the images available at 0625 , 0805, and 1240 UTC 10 October, it was clear that L1 


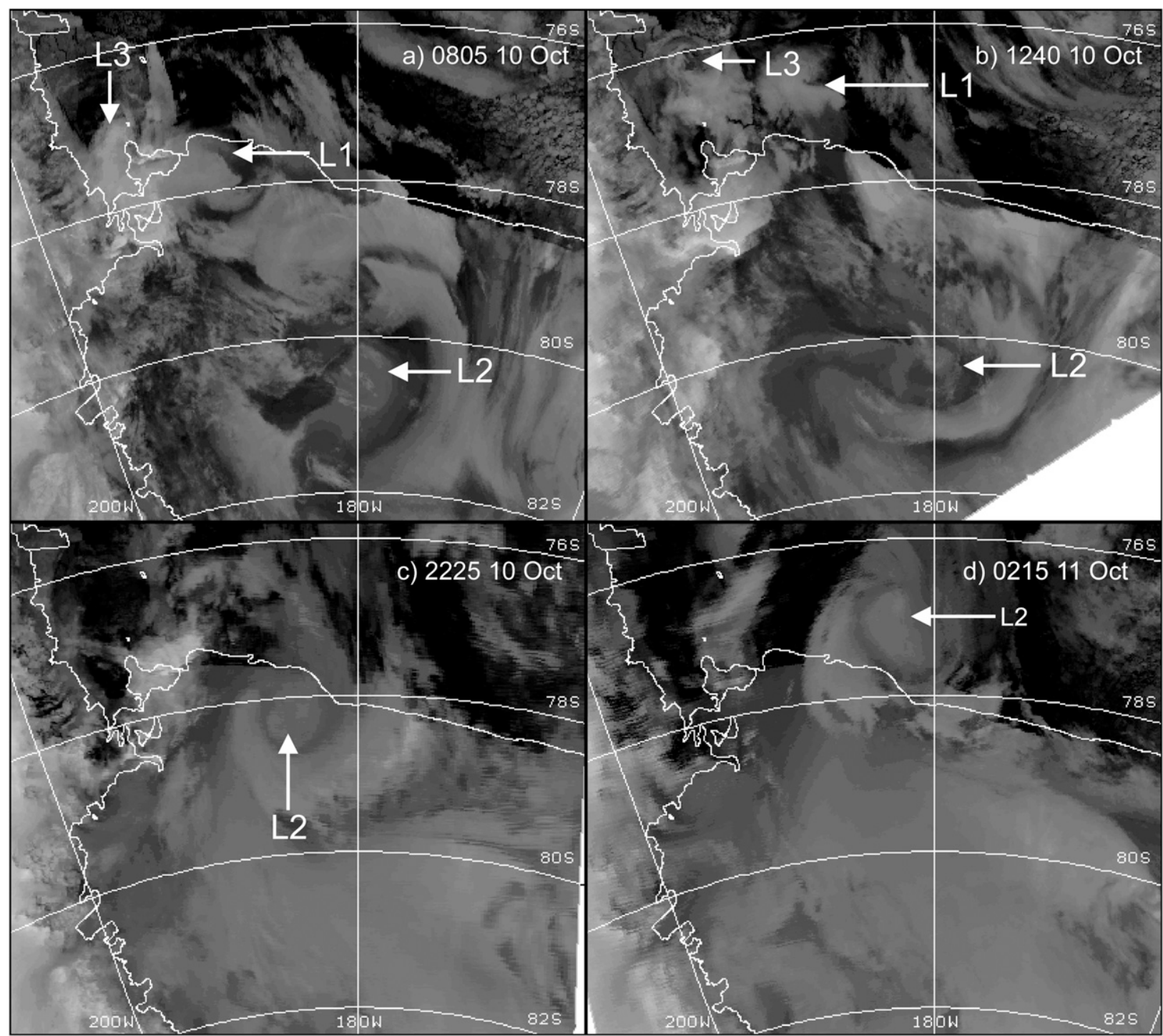

FIG. 4. The MODIS infrared satellite images at (a) 0805, (b) 1240, and (c) 2225 UTC 10 Oct 2003, and (d) 0215 UTC 11 Oct 2003.

tracked in a northwesterly initially and then northeasterly direction to the Ross Sea, east of Ross Island and was visible as a comma cloud (Figs. 4a,b). Many mesoscale low pressure systems in the polar regions have such a comma-shaped cloud band associated with them (Rasmussen and Turner 2003). Lows L1 and L3 were only visible at 1240 UTC 10 October (Fig. 3b) and subsequently disappeared from the satellite image by 1415 UTC 10 October. At 1800 UTC 10 October 2003, the central pressure of L2 was found to be deeper $(<968 \mathrm{hPa})$ in the manual analysis (Fig. 6c) than indicated by the ERA-Interim reanalysis (Fig. 5c. At 1800 UTC, the pressure gradient around the station intensified due to the strengthening of the high pressure as well as tracking of low pressure system L2 toward the station (Figs. 6b,c). Over the next $6 \mathrm{hL} 2$ tracked toward the northwest and then to the northeast (see Figs. 3 and 4b-d) and arriving over the Ross Sea by 0215 UTC 11 October 2003 (Figs. 4b,c). L2 dissipated when it reached the Ross Sea, northeast of Ross Island.

The AMPS forecast suggests that a low pressure system, L2, formed on the Ross Ice Shelf from a preexisting trough at 1500 UTC 9 October 2003. The low then tracked generally northwestward across the Ross Ice Shelf. AMPS simulated the development (Fig. 7) of L1 as well as L2. However, the position of L2 was slightly to the west in the AMPS forecast compared with the location on the satellite imagery (Figs. 7a,b). The subsequent forecasts from AMPS suggested that L2 had a 


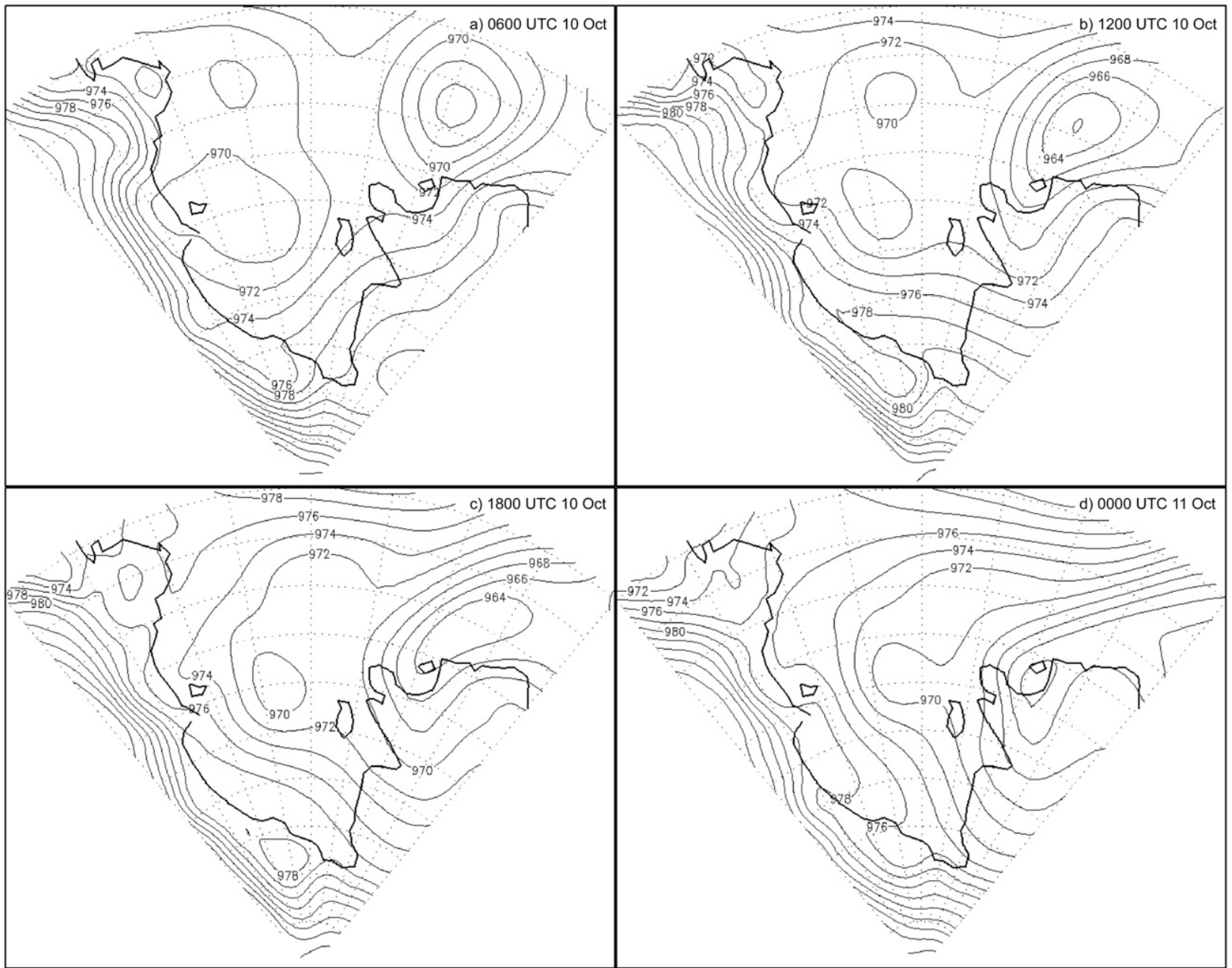

FIG. 5. ERA-Interim MSLP (hPa) analysis at (a) 0600, (b) 1200, and (c) 1800 UTC 10 Oct 2003, and (d) 0000 UTC 11 Oct 2003.

central pressure of $968 \mathrm{hPa}$ and tracked northwestward until 1800 UTC and then took a northeastward track. After 2100 UTC, the track of L2 in the AMPS simulations was found to be slightly to the east compared to the satellite imagery (Figs. 7c,d).

The wind speed started to increase at WF-AWS1 after 0630 UTC 10 October 2003, when the mesoscale lows L1 and L3 were located south of Ross Island near to the station. The wind speed measured by the WFAWS1 showed a steady increase after 1100 UTC 10 October 2003 (Fig. 8). A shift in the wind direction from north-northwest to north-northeast to southerly was observed around this time in the AWS data from WF-AWS1. The shift in the wind direction to southerly at WF-AWS1 is due to the changes in stability and wind speed (Seefeldt et al. 2003) explained in detail in section 5 . The first peak observed in the wind speed was $16 \mathrm{~m} \mathrm{~s}^{-1}$ at 1600 UTC 10 October, when the low L2 showed an organized cloud pattern. The duration of this event was approximately $11 \mathrm{~h}$ starting from 1200 UTC 10 October.

Strengthening in the wind speed was also accompanied by a rapid increase in temperature and relative humidity from $-26^{\circ}$ to $-22^{\circ} \mathrm{C}$ and from $81 \%$ to $88 \%$, respectively. This denotes the involvement of maritime recirculated air during the event. In the satellite image, L2 was seen to have moved toward Ross Island and at 1540 UTC L2 showed disorganized cloud and signs of slight weakening. However, the imagery for 1910 and 2225 UTC (Fig. 4c) showed a more organized cloud signature associated with the deepening of the system. At 1800 UTC 10 October 2003, the stationary high pressure system over the west of the study area strengthened and the pressure gradient near the station intensified. (Fig. 6c). The MODIS image at 2225 UTC 10 October (Fig. 4c) shows a clear spiraliform cloud signature just to the eastern side of Ross Island, which confirms the existence and track of L2. 


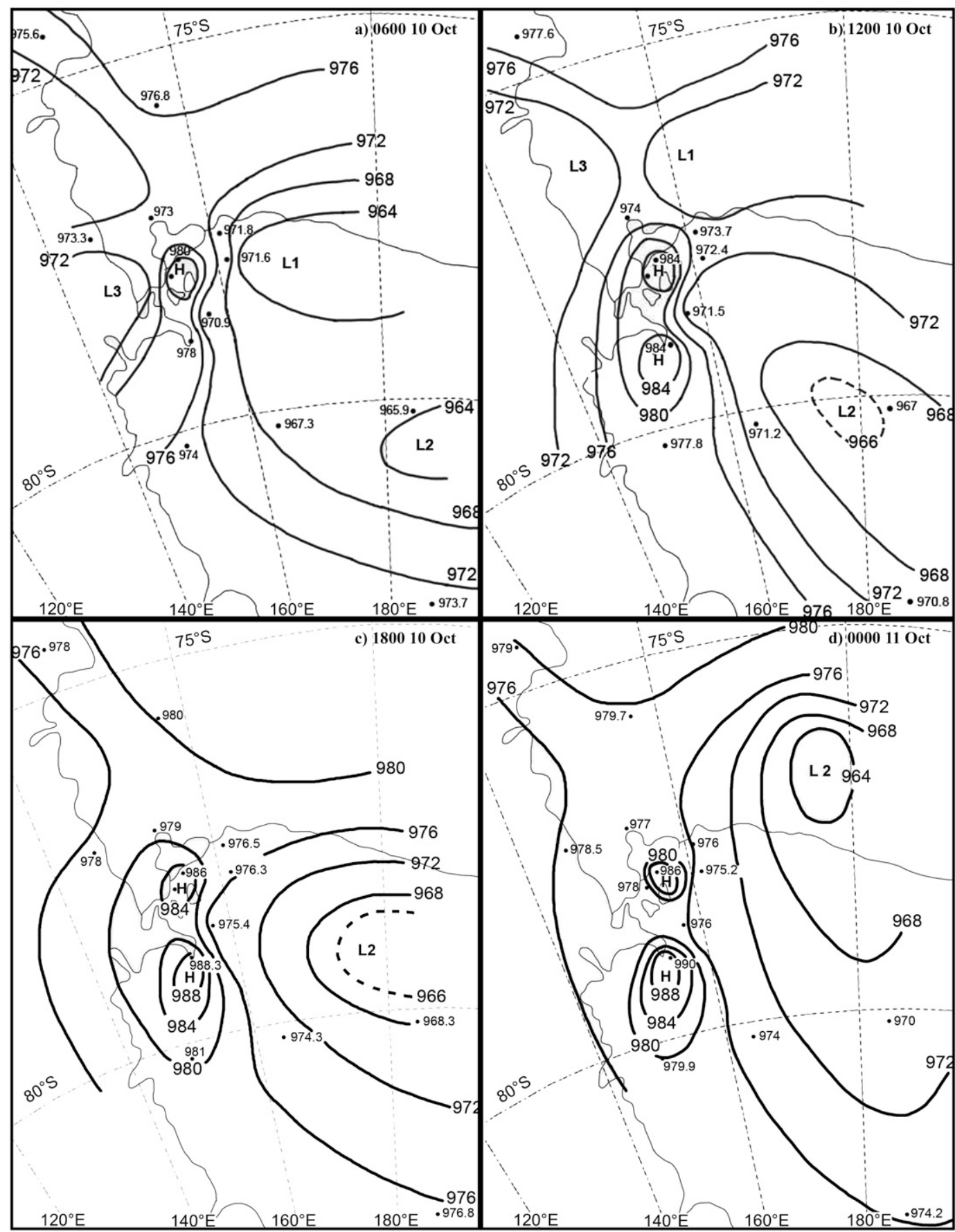

FIG. 6. MSLP analysis (hPa) (based on AWS and satellite images) at (a) 0600, (b) 1200, and (c) 1800 UTC 10 Oct 2003, and (d) 0000 UTC 11 Oct 2003.

The next available satellite image at 0215 UTC 11 October (Fig. 4d) showed L2 over the Ross Sea north of the shelf. On 11 October the wind speed remained below $10 \mathrm{~m} \mathrm{~s}^{-1}$ with the wind direction shifting from southerly to northeasterly. Although the pressure dropped from 976 to $971 \mathrm{hPa}$ (Fig. 8) there was no increase in wind speed during 11 October 2003. A decrease in temperature and rapid fluctuations in the humidity were also observed during the period.

\section{An airflow analysis for the SWE}

A potential vorticity (PV) analysis was carried out for the SWE in order to examine the interactions 


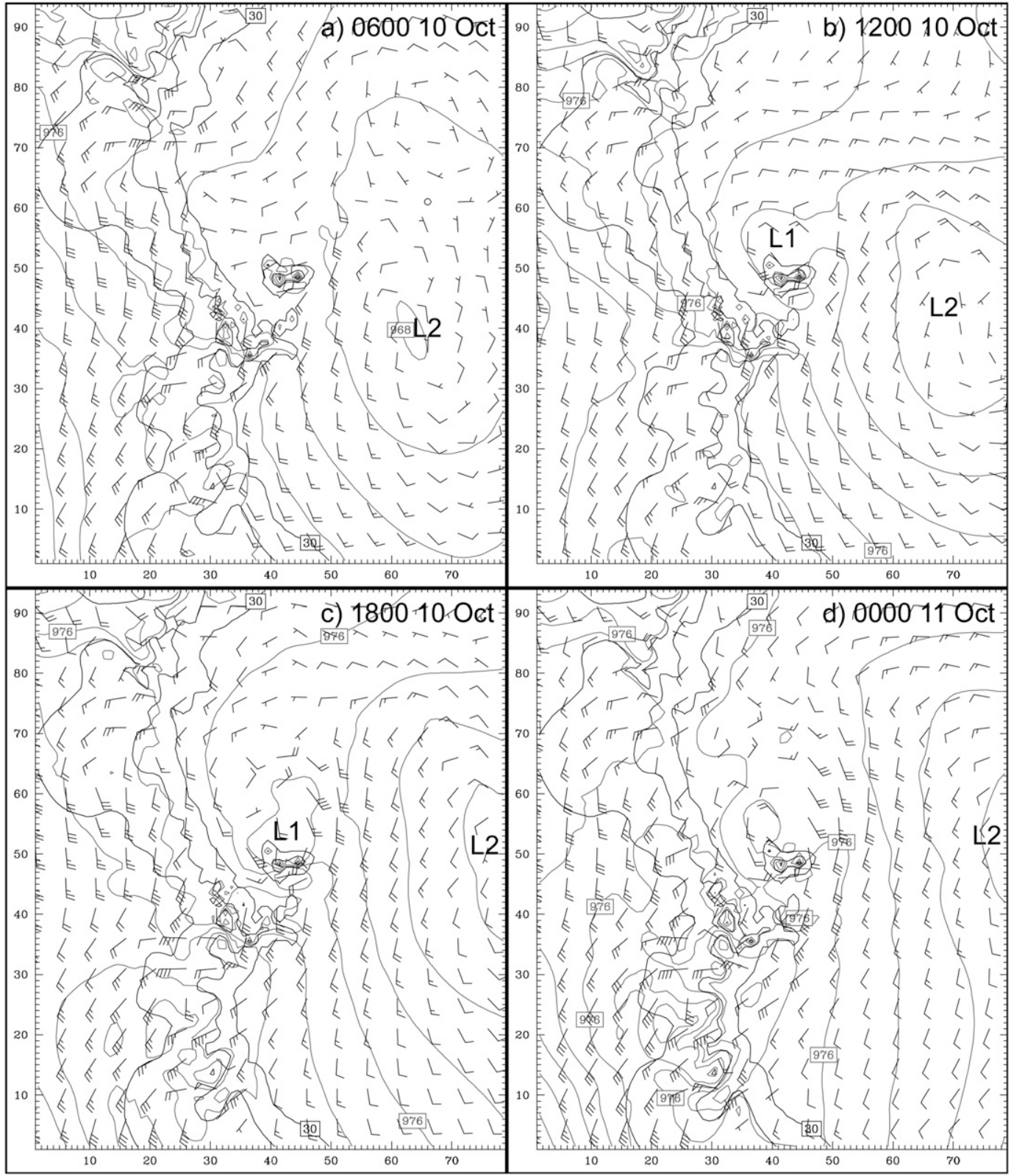

FIG. 7. MSLP and surface wind analysis at (a) 0600 and (b) 120010 Oct 2003 (initialized at 0000 UTC 9 Oct 2003) and at (c) 1800 UTC 10 Oct and (d) 0000 UTC 11 Oct 2003 (initialized at 0000 UTC 10 Oct 2003) from the 10-km AMPS grid (full barb indicates $5 \mathrm{~m} \mathrm{~s}^{-1}$ ).

between katabatic drainage flow from the interior of the continent and maritime air masses. During a SWE over the northwest Ross Ice Shelf, it is difficult to differentiate the possible involvement of katabatic flow from the flow initiated by the passage of depressions from the wind direction alone, since the wind direction is predominantly from the south during most of the events. Therefore, the concept of PV can be applied as a tracer element to differentiate katabatic wind from barrier wind and cyclonic circulations. In the Southern Hemisphere a positive PV is associated with cold anticyclonic air and negative potential vorticity with the cyclonic circulation (Hoskins et al. 1985; Basset and Ali 2006) and barrier wind. In a homogeneous fluid with constant density, the potential vorticity is a conserved quantity (Davis and Emanuel 1991). The potential vorticity is given by

$$
(\zeta+f) / \delta z=\text { constant },
$$

where $\zeta$ is the relative vorticity, $f$ is the Coriolis parameter (negative in the Southern Hemisphere), and $\delta z$ 


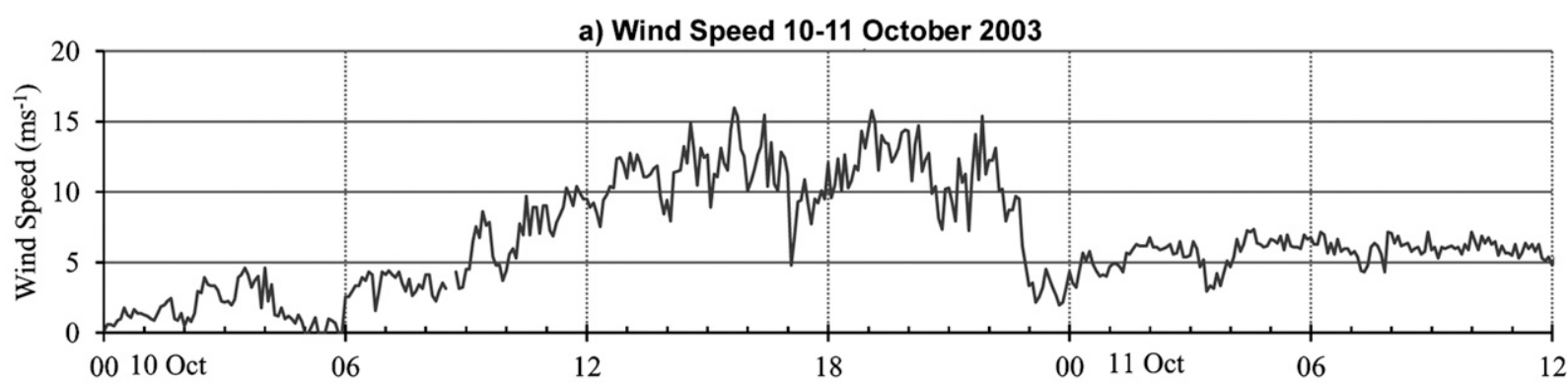

b) Wind Direction 10-11 October 2003

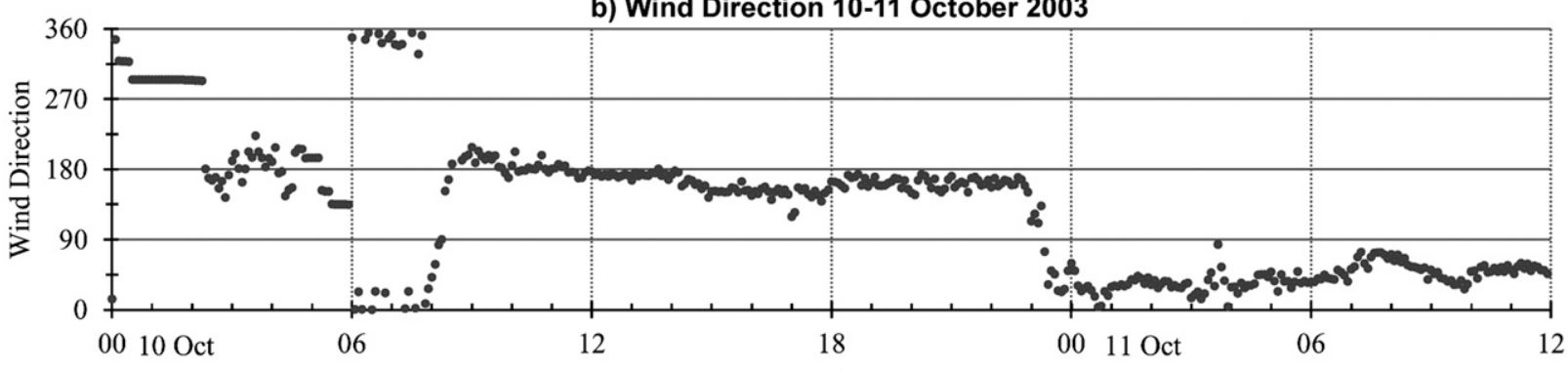

c) Pressure 10-11 October 2003

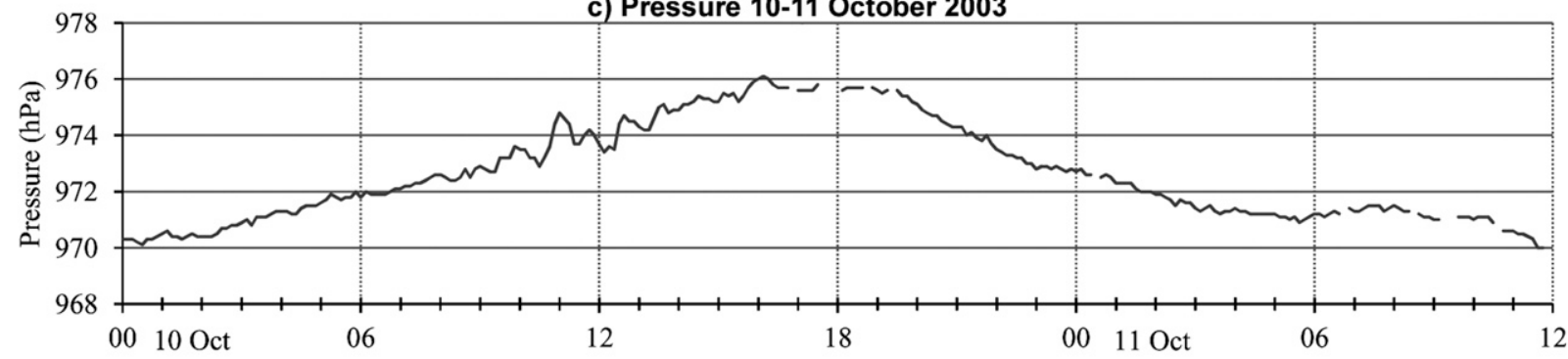

d) Temperature 10-11 October 2003

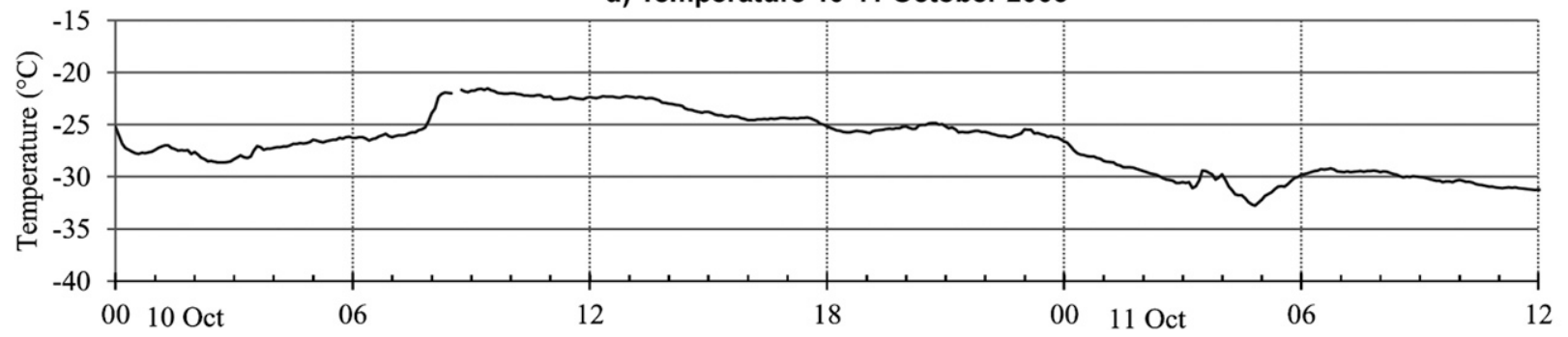

FIG. 8. Time series of meteorological parameters from the WF-AWS1 over the period 10-11 Oct 2003.

is the depth of the air column. As a result, the amount of potential vorticity possessed by an air mass is unaffected by changes of elevation, latitude, or shear. Therefore, PV can be used as a tracer element to differentiate the involvement of cyclonic or anticyclonic air masses during a SWE. To resolve the synoptic-scale interactions, 30-km horizontal resolution simulations from AMPS have been utilized. The vertical cross section of potential vorticity distribution between $85.5^{\circ} \mathrm{S}, 166^{\circ} \mathrm{E}$ (continental slope south of Ross Ice Shelf) and $77.5^{\circ} \mathrm{S}$, $166^{\circ} \mathrm{E}$ (Ross Island) were used in Figs. 9a and 9b. In these figures, RI and CS represent the Ross Island and the continental slope south of the Ross Ice Shelf, respectively. The synoptic-scale analysis showed that there was an interaction between the cyclonic storm with the drainage flow from the south.

Figure 9a shows the PV analysis at 0000 UTC 10 October 2003. It can be seen that at the surface there was a katabatic drainage of cold air from the south denoted by positive potential vorticity (shaded purple to blue) and maritime air with cyclonic potential vorticity from the Ross Sea area (shaded red to yellow) as well as over the slope of the continent. The PV analysis at 1200 UTC October 2003 showed enhancement of drainage flow from the south (not shown). The flow accelerated toward Ross Island due to deepening of the depression, 

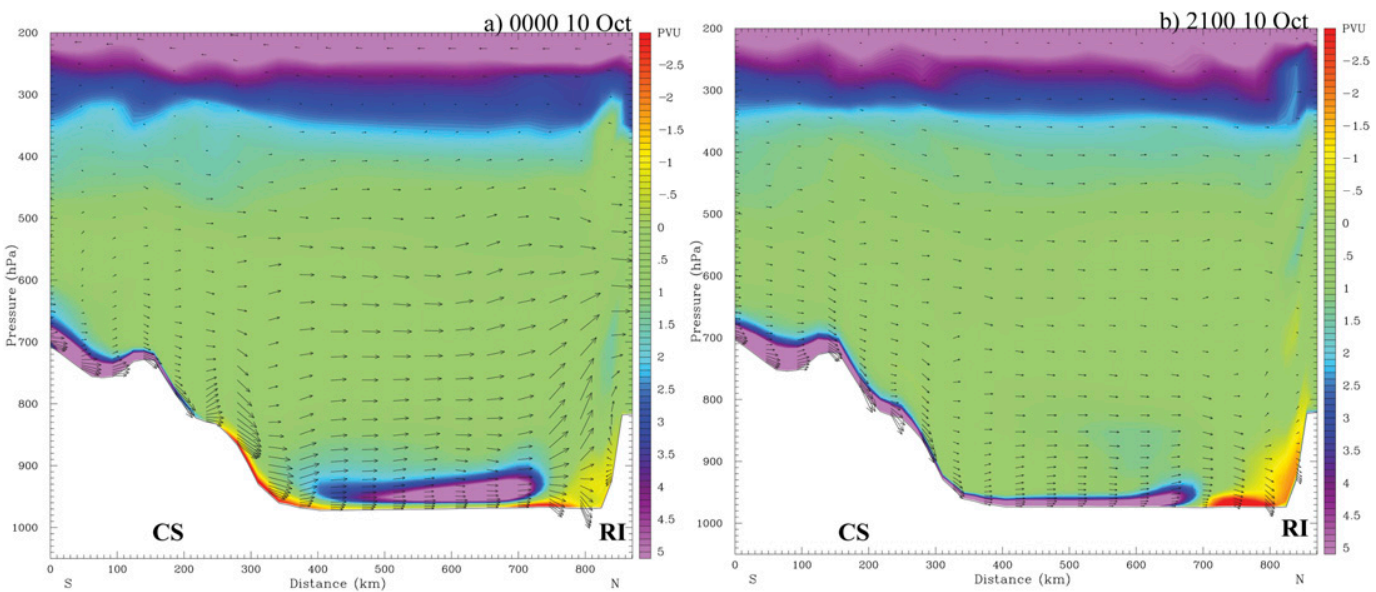

FIG. 9. Cross section (from $85.5^{\circ} \mathrm{S}, 166^{\circ} \mathrm{E}$ to $77.5^{\circ} \mathrm{S}, 166^{\circ} \mathrm{E}$ ) of potential vorticity and the resultant of meridional component of the horizontal wind and the vertical wind vector from the 30-km AMPS grid (initialized at 1200 UTC 9 Oct 2003) at (a) 0000 and (b) 2100 UTC 10 Oct 2003.

which is denoted by the strengthening positive vorticity present over Ross Island. Note that there was also an uplift of cold air. Many earlier studies (Bromwich et al. 1992; Bromwich et al. 1994; Breckenridge et al. 1993) reported such drainage flows on the Ross Ice Shelf, which are initiated by synoptic-scale weather systems.

Figure $9 \mathrm{~b}$ shows the PV simulation for 2100 UTC 10 October 2003. This shows that the area of the drainage flow was more limited to southerly locations and in the meantime there was an intensification of cyclonic vorticity near Ross Island. At this point the entire continental slope was under the influence of an air mass of anticyclonic vorticity. At around this time, the satellite image showed the passage of the synopticscale low (L2) just to the eastern side of Ross Island (see Fig. 4c).

As noted earlier, the AMPS model horizontal resolution was $30 \mathrm{~km}$ in order to represent the large-scale forcing reasonably. But this simulation failed to resolve the topographic features of Minna Bluff and Black and White Islands. Therefore, the actual horizontal extent of the anticyclonic vorticity or the katabatic drainage flow on the Ross Ice Shelf may be much less than in the simulations since there can be more blocking produced by these features. From the analysis it is evident the SWE was not associated with the katabatic drainage flow since air of continental origin did not reach McMurdo Station/Ross Island region and it was the recirculated maritime air coming up from the south around low pressure system L2 and hitting BI and WI. It flowed around the island at first and then had sufficient energy to cross it starting the SWE at McMurdo Station to the north.

\section{Details of the wind flow over the northwest Ross Ice Shelf during the SWE}

To understand specific features and the dynamics of the wind flow around the Ross Island region, the Froude number (Fr), upper-air soundings from McMurdo Station, and selected forecasts from the AMPS output archive were used. If $\mathrm{Fr}<1$ the static stability dominates over inertia, therefore the flow will not have sufficient kinetic energy to override topography, whereas if $\mathrm{Fr}>1$ the flow will be able to override a barrier. The value of the Fr number was calculated using data from the radiosonde ascent at 2200 UTC 9 October before the SWE and at 1120 UTC 10 October 2003 during the event. At 2200 UTC 9 October Fr was found to be 0.492; therefore, the recirculated maritime air coming from the south lacked the energy to flow over the topographical features and must instead flow around it (Seefeldt et al. 2003; Chenoli et al. 2012). In this scenario McMurdo Station will experience northwesterly wind as shown in Fig. 10a. At 1120 UTC 10 October 2003, Fr was 1.48, a supercritical wind, and indicated that the wind flow was able to flow over the obstacle, giving southerly winds at over the study area.

Figure 10a shows wind vectors when the Fr was less than 1 at 1800 UTC 9 October 2003. The wind directions over the area south of Black and White Islands were not southerly since the flow could not override the topography. The general surface wind flow over the area south of Minna Bluff was from the southwest and the major part of the surface flow was deflected by Minna Bluff. In addition, northwesterly flow was evident on the south of Black and White Islands with predominantly light wind speeds over the area south of Ross Island. Therefore, 


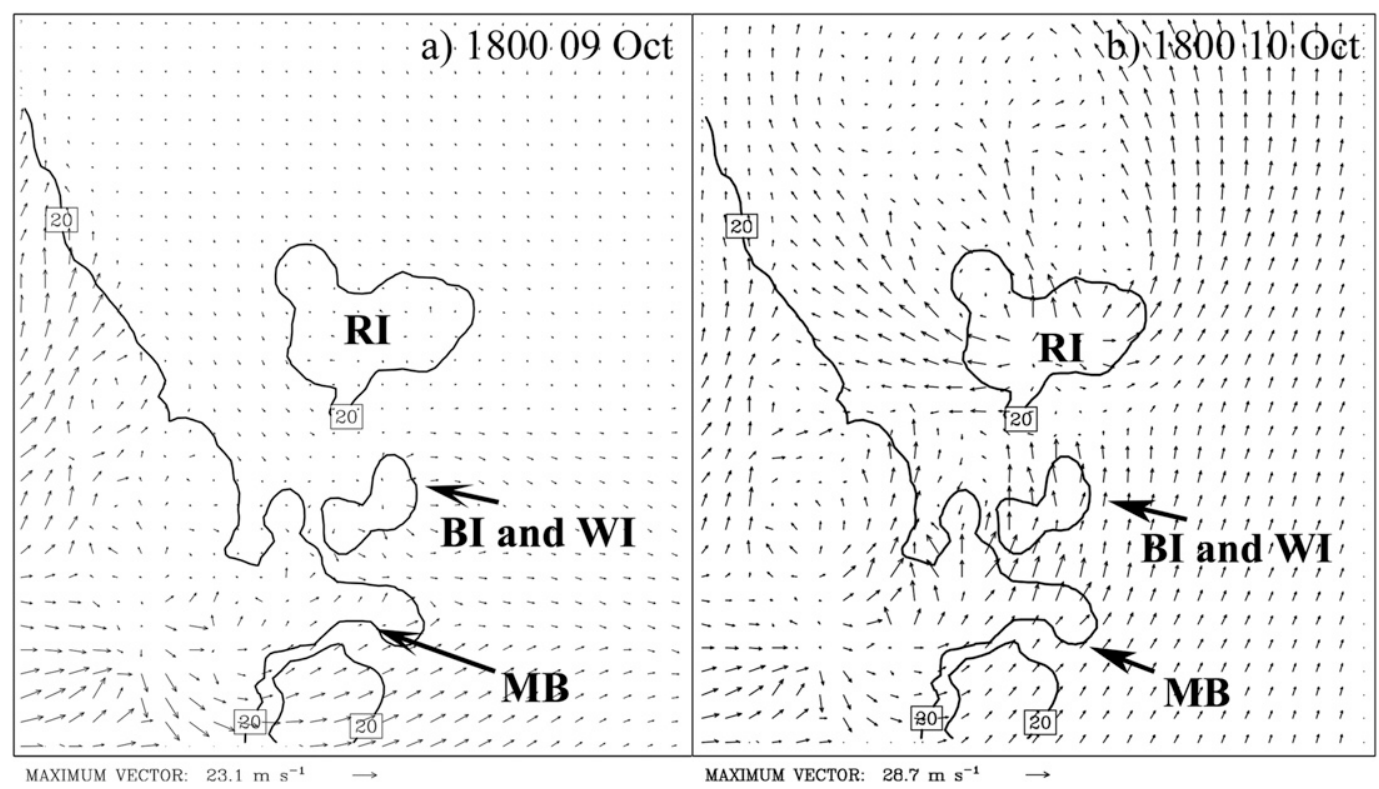

FIG. 10. Surface wind vectors (maximum wind vector $23 \mathrm{~m} \mathrm{~s}^{-1}$ ) from 3.3-km AMPS grid at (a) 1800 UTC 9 Oct 2003 (initialized at 0000 UTC 9 Oct 2003) and (b)1800 UTC 10 Oct 2003 (initialized at 0000 UTC 10 Oct 2003); RI, BI, WI, and MB denote Ross Island, Black Island, White Island, and Minna Bluff respectively.

when the Fr number was less than 1 the wind direction over the northeastern part of Ross Ice Shelf showed a topographical influence. With Fr greater than 1 and during high wind speeds, the wind vectors showed (Fig. 10b) southerly winds throughout the Ross Island region. During these conditions, the wind flow had sufficient energy to flow over the topographic obstacles such as Minna Bluff and Black and White Islands. Therefore, during the high wind period the wind direction did not exhibit much topographical influence south of Ross Island. On the contrary, the simulation showed that the surface flow splits around Ross Island creating the calm zone at the Windless Bight area during the SWE.

Both Figs. 10a and 10b show outflows of katabatic drainage through the glacier passes of the Transantarctic Mountains. The MODIS satellite imagery at this time also showed the black signatures of katabatic winds in the infrared channel (Bromwich 1989, 1992). The propagation of katabatic wind across the Ross Ice Shelf was enhanced by the passage of the low pressure systems across Ross Ice Shelf (Fig. 3). There are also indications of katabatic outflow being drawn into the circulation of low L2 (Fig. 4c. However, as shown by the PV analysis as well as the AWS data, the McMurdo Station/Scott Base area was not affected by katabatic drainage flow during the SWE.

\section{a. The mechanisms behind the development of the SWE}

Analysis of the vertical cross section of potential temperature from the AMPS forecasts suggests possible association with mountain wave activity during the SWE over the area of study. To investigate the involvement of mountain wave amplification and the formation of a down slope winds during the SWE, the available radiosonde data from McMurdo Station were used (Fig. 11). The generation of such winds can be attributed to a range of conditions that allows trapping of wave energy by two or more neutrally stratified layers with sharp inversions at each layer interface (Klemp and Lilly 1975). The potential temperature from the upper-air data showed deviation from the multilayer model given by Klemp and Lilly (1975). Therefore, it is not appropriate to consider the mechanism of amplification of wave energy due to the partial reflection by the variation in thermal stability (Klemp and Lilly 1975). Lindzen and Tung (1976) suggested that wind shear enhances the reflectivity and critical layer can be defined as the layer where the flow speed is equal to the phase speed of the wave. To calculate the phase speed of the propagation wave, the time series data from AWSs WF-AWS1 and WFAWS2 were used. WF-AWS1 and WF-AWS2 are $1 \mathrm{~km}$ apart on Williams Field near Scott Base. The time lag between the coherent signature in the time series of temperature obtained from WF-AWS1 and WF-AWS2 was determined assuming the wave to be propagating northward. An approximate phase speed of propagation of the wave was calculated from the time lag and the distance between the two AWSs. Since the time lag between the coherent signatures in 

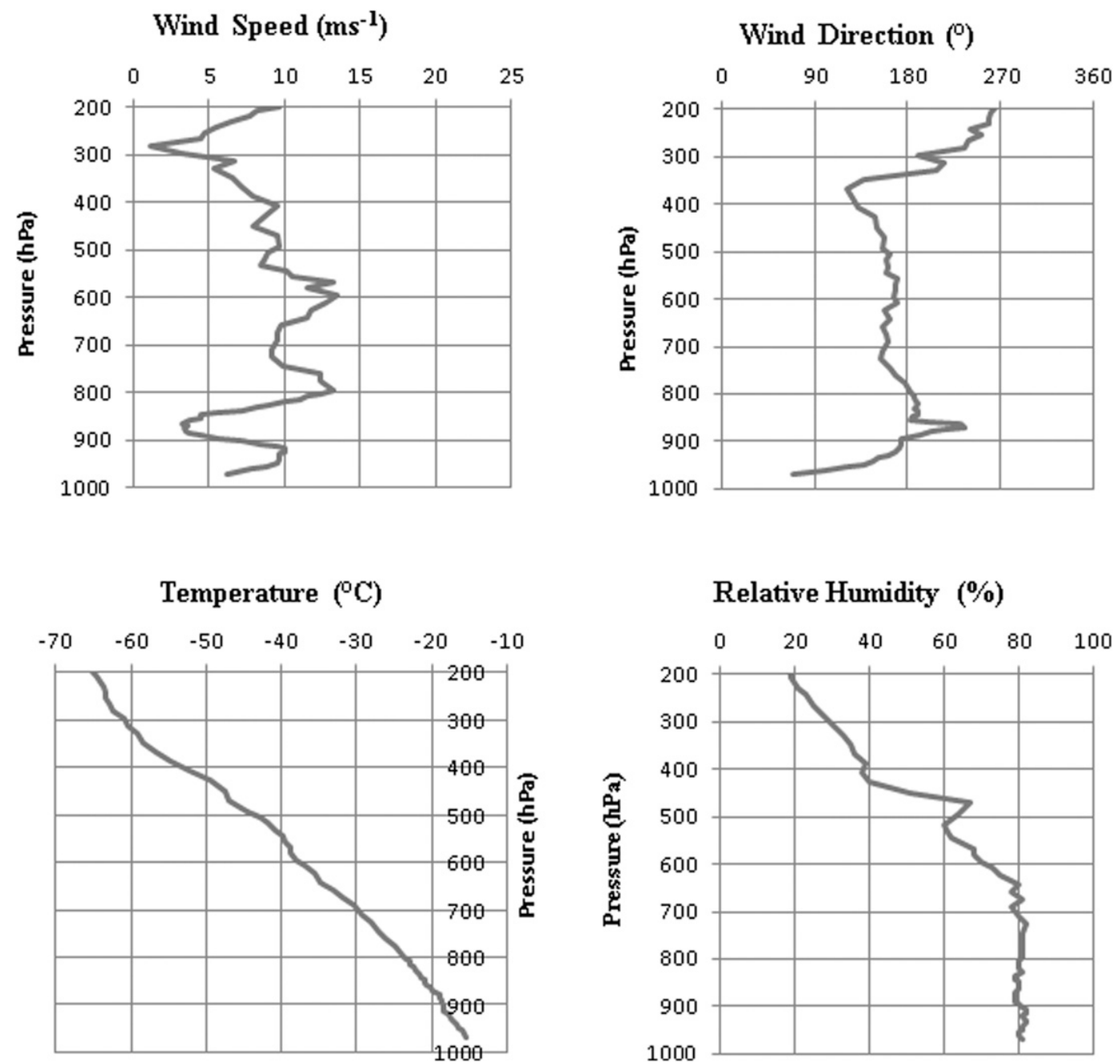

FIG. 11. Vertical profiles from McMurdo Station at 1100 UTC 10 Oct 2003.

the time series of temperature from WF-AWS1 and WF-AWS2 is $2 \mathrm{~min}$ and the distance between the AWSs is $1 \mathrm{~km}$, the phase speed of the wave was given by the following:

$$
C=\frac{1000}{2 \times 60}=8.36 \mathrm{~m} \mathrm{~s}^{-1} .
$$

Therefore, the self-induced critical layer can be present between the layers at $550-500$ or $500-400 \mathrm{hPa}$ when the wind speed is about $8 \mathrm{~m} \mathrm{~s}^{-1}$. When the mountain waves break at this level it can create turbulence and a deflection of energy back toward the surface.

The Richardson number Ri was calculated using the formula given below [Eq. (2)] in order to get a clear measure of atmospheric instability. The Richardson number is defined as

$$
\mathrm{Ri}=\frac{\frac{g \partial \theta}{\theta \partial z}}{\left(\frac{\partial U}{\partial z}\right)^{2}+\left(\frac{\partial V}{\partial Z}\right)^{2}},
$$

where $g$ is the acceleration due to gravity, $\theta$ the potential temperature, $U$ the east-west component of the wind, $V$ the north-south component of the wind, and $z$ the height. The atmospheric conditions are favorable for the occurrence and maintenance of turbulence when $\mathrm{Ri}<$ the critical Richardson number (i.e., $\mathrm{Rc} \leq$ 0.5; Keliher 1975). Some of the previous works of Hoskins (1971) used $\mathrm{Rc}=0.1$ as an indication of instability. The Ri value between the levels 567 and $555 \mathrm{hPa}$ was found to be 0.5 , which is indicative of shear instability at this layer (Keliher 1975). Therefore, when the strong winds from the south were able to override the mountain barrier, vertically propagating waves 


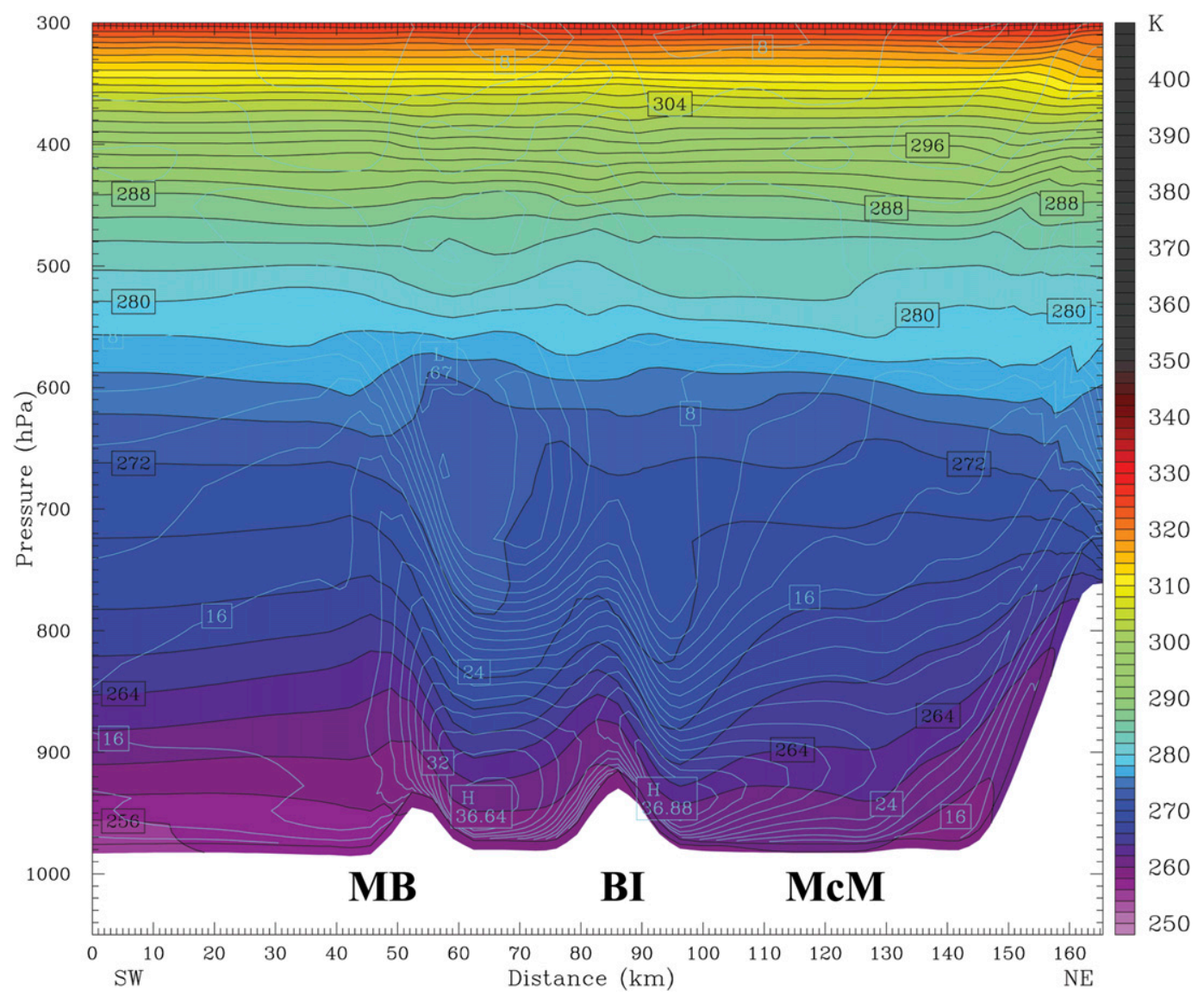

FIG. 12. Cross section $\left(79^{\circ} \mathrm{S}, 166^{\circ} \mathrm{E}\right.$ and $\left.77.5^{\circ} \mathrm{S}, 167^{\circ} \mathrm{E}\right)$ of potential temperature (contour interval $2 \mathrm{~K}$ ) and horizontal wind speed (white lines, $2 \mathrm{~m} \mathrm{~s}^{-1}$ ) from the AMPS 3.3-km grid (initialized at 0000 UTC 10 Oct 2003) at 1500 UTC 10 Oct 2003. (For location of the transect see Fig. 1).

from the upslope flow were generated. These waves can be reflected by the self-induced critical level at about $555 \mathrm{hPa}$ sending the waves and all its energy back toward the surface where it can be amplified to generate downslope high wind.

Figure 12 shows the vertical cross section of horizontal wind speed from the AMPS 3.3-km run at 1500 UTC 10 October 2003. The figure indicates a core of high wind speed on the leeward side of Minna Bluff and Black and White Islands that extended over the McMurdo Station area. The vertical cross section of wind speed and vertical potential temperature distributions from AMPS output (Fig. 12) showed the wave structure over Minna Bluff and Black Island.

The vertical cross sections $\left(79^{\circ} \mathrm{S}, 166^{\circ} \mathrm{E}\right.$ and $77.5^{\circ} \mathrm{S}$, $167^{\circ} \mathrm{E}$ ) of potential temperature and wind field pattern show similarities to those found in other observational and modeling studies of downslope windstorms in various other parts of the world (Klemp and Lilly 1975) (see Fig. 12). Common features are strong winds along the lee slope, as well as downward-sloping potential temperature field (see Fig. 12). Figure 13 shows a cross section (for the location of the transect, see Fig. 1) of potential temperature (contoured, interval $2 \mathrm{~K}$ ) and meridional and vertical component of wind vector from AMPS $3.3-\mathrm{km}$ grid at 1500 UTC 10 October 2003. At lower levels, the wind speed and direction over the area showed the influence of the orography (see Figs. 12 and 13). At around $500 \mathrm{hPa}$, the wave pattern in the potential temperature is not evident and the layer above showed a reverse wind shear, indicating model representation of self-induced critical level (see Fig. 13). This critical level halts the vertical propagation of the mountain waves and sends it back toward the surface. Downslope windstorms are a common feature (Steinhoff et al. 2008) along the slopes of Minna Bluff and Black and White Islands. These storms affect McMurdo Station/Ross Island region whenever there are strong southerly winds and low level inversions. Steinhoff et al. (2008) investigated a severe storm, which was one of the rare extreme wind events to strike McMurdo Station in recorded history (Powers 2007). The severe storm was associated with the 


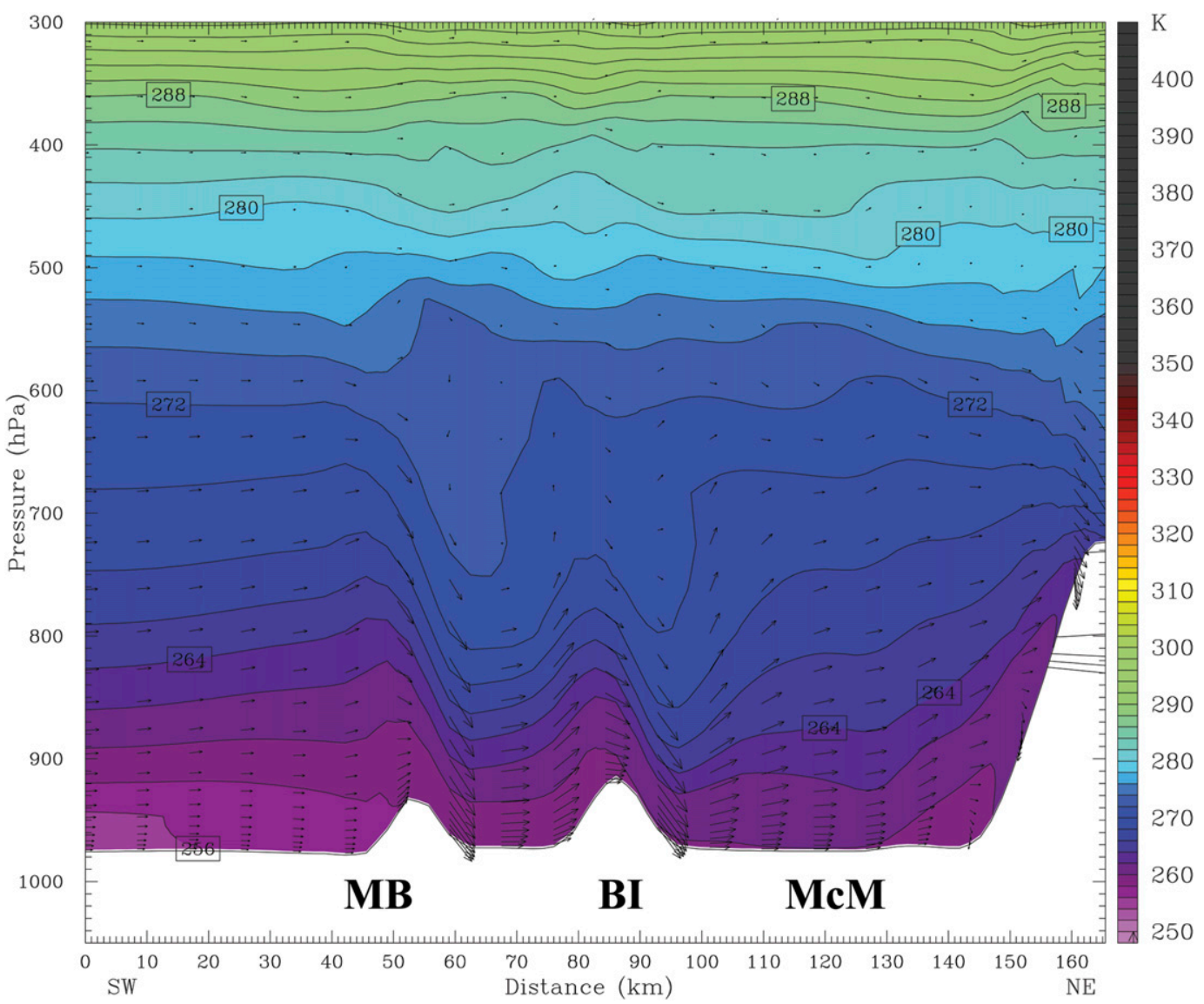

FIG. 13. Cross section $\left(79^{\circ} \mathrm{S}, 166^{\circ} \mathrm{E}\right.$ and $\left.77.5^{\circ} \mathrm{S}, 167^{\circ} \mathrm{E}\right)$ of potential temperature (contoured, interval $2 \mathrm{~K}$ ) and the horizontal and vertical components of wind vector from AMPS 3.3-km grid initialized at (0000 UTC 10 Oct 2003) at 1500 UTC 10 Oct 2003. (For location of the transect see Fig. 1).

barrier jet, and downslope windstorms with amplification of the mountain waves caused by wave-breaking events. They had analyzed all the processes and features associated with the development of the severe wind storms and concluded that the major contribution of the event was from the downslope windstorms. On the other hand, in the case study presented here, we have considered an SWE based on our statistically defined wind strength from climatological analysis (1979-2002) of the available station data from McMurdo Station (Chenoli et al. 2012). The main focus of this study is to understand the processes and characteristics of the commonly observed strong wind events in the region. This study is an example of an SWE due to the tightening of the pressure gradient across the western Ross Ice Shelf caused by the propagation of three low pressure systems across the Ross Ice Shelf as well as the intensification of the high pressure system over the western part of the study area. This enabled the enhanced southerly flow to override the topographical barriers to develop into a downslope wind and the formation of mountain wave, both concurrently leading to the occurrence of the SWE. However, a good observation network near McMurdo Station/Ross Ice Shelf region as well as higher horizontal resolution model run would be necessary to gain better insights into such events.

\section{b. The performance of AMPS in simulating the SWE}

AMPS performed well in stimulating the synoptic environment of the SWE, as it forecast key aspects of this event such as the position of two of the low pressure systems, movement and other local features such as the splitting of the surface wind around the Ross Island (see Fig. 10b), and the development of the downslope winds (see Figs. 12 and 13). During the SWE the AMPS analysis produced two mesoscale pressure systems L1 and L2 and failed to produce L3. Figure 14 shows the MODIS image at 1120 UTC overlaid with the nearest MSLP (white contour) analysis available from the $30-\mathrm{km}$ AMPS domain at 1200 UTC 10 October. To assess the performance of AMPS further, time series of wind speed and pressure from the AMPS $3.3-\mathrm{km}$ 


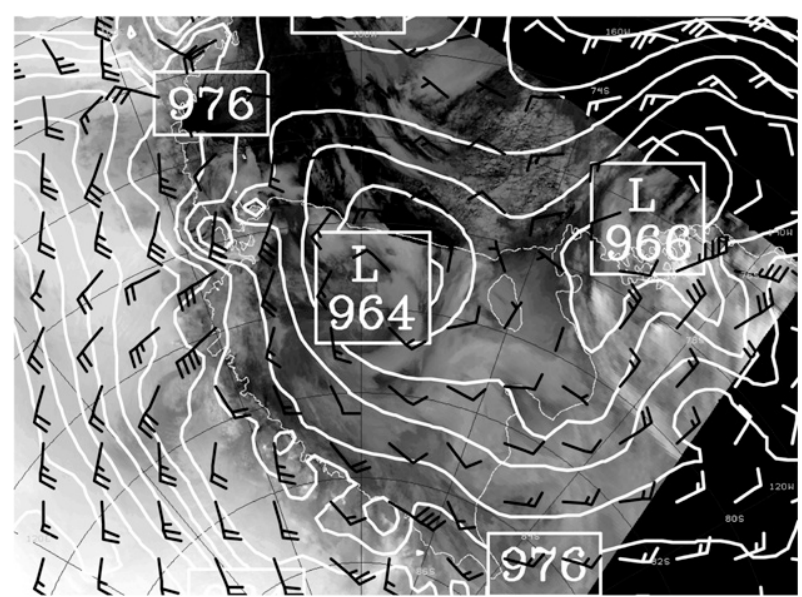

FIG. 14. MSLP analysis and surface wind and from $30-\mathrm{km}$ grid of AMPS output at 1200 UTC (initialized 1200 UTC 9 Oct 2003) and MODIS image at 1120 UTC 10 Oct 2003.

domain have been compared with the observational data. Figure 15 shows a time series of the MSLP values from the WF-AWS1 and time series of pressure from the $3.3-\mathrm{km}$ AMPS forecasts at the corresponding location. AMPS output showed higher pressure than observed values and there was a time difference of $4 \mathrm{~h}$ between the two time series in recording the maximum value with a root-mean-square error (RMSE) of $1.4 \mathrm{hPa}$. The AMPS forecast overestimated the observed wind speed with differences in wind speed as large as $4 \mathrm{~m} \mathrm{~s}^{-1}$ (Fig. 16) at the beginning of the forecast period and then the magnitude was comparable.

\section{Conclusions}

The analysis of AWS data showed that a SWE affected the McMurdo Station/Scott Base area on
10 October 2003. The maximum wind speed noted during the event was $16 \mathrm{~m} \mathrm{~s}^{-1}$ with duration of $11 \mathrm{~h}$ with a wind speed above $10 \mathrm{~m} \mathrm{~s}^{-1}$. The SWE was associated with the passage of mesoscale lows (L1 and L3) and L2 approximately 600-km diameter (L2) across the Ross Ice Shelf. Of the three lows, L2 exerted the most influence and was distinctive on the satellite image and model output. Katabatic drainage flow formed as the low pressure system propagated across the Ross Ice Shelf, which was identified in the MODIS images as dark signatures. It is evident from AWS data and PV analysis at the McMurdo Station/Scott Base area that there was no involvement of drainage flow during SWE. The strengthening of the pressure gradient across the western Ross Ice Shelf was caused by the propagation of the low pressure systems across the Ross Ice Shelf, which allowed the enhancement of southerly flow to override the topographical barriers. The AMPS simulations showed the development of large-amplitude vertically propagating mountain waves over the area. The amplification of mountain waves by the self-induced critical level reflected the energy back toward the surface to generate high downslope wind. AMPS provided a credible forecast with slight biases in low pressure tracks and wind speeds. Downslope winds appear to be a very important component of the SWE in the Ross Island region, although more needs to be known about their development. There are several possibilities for further work in this area. A more detailed observational or modeling study focused on downslope winds and the subsequent impact on McMurdo Station would be necessary for the improved understanding of the processes involved in the development of downslope wind. This will provide improvement of local forecasting and severe wind warnings.

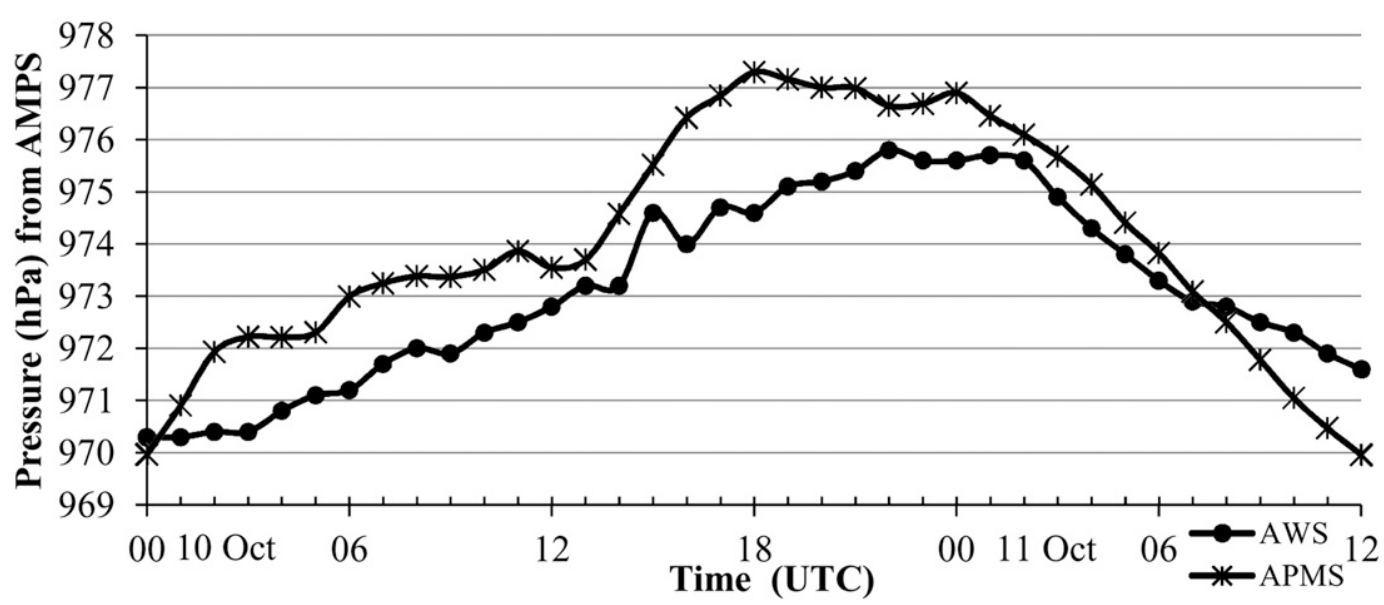

FIG. 15. Time series of mean sea level pressure (hPa) from WF-AWS1 and AMPS 3.3-km grid. 


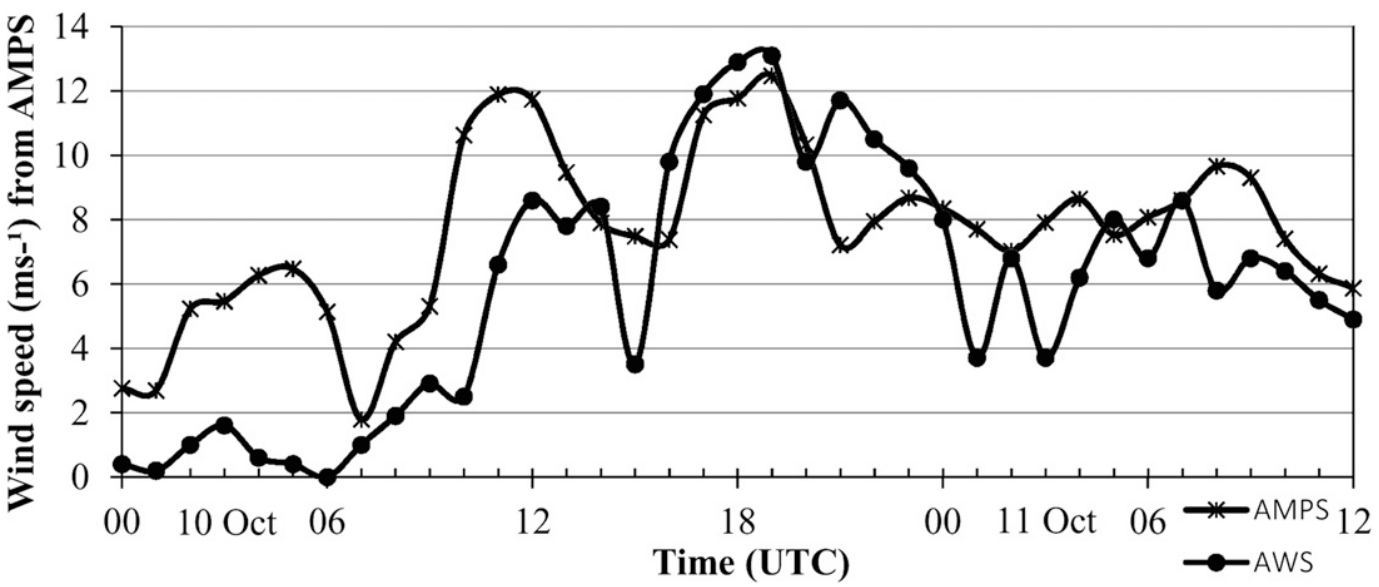

FIG. 16. Time series of wind speed $\left(\mathrm{m} \mathrm{s}^{-1}\right)$ from WF-AWS1 and AMPS 3.3-km grid.

Acknowledgments. This study was funded by the Malaysian Antarctic Research Program, Academy of Sciences, Malaysia (ASM), Ministry of Science Technology and Innovation (MOSTI) Grant FP1213E037 and University of Malaya Research Grant (RP002B-13SUS). The authors would also like to thank Dr. John Cassano, Cooperative Institute for Research in Environmental Sciences, University of Colorado, for the initial discussions on this project and providing an access to AMPS archive. We would also like to thank Dr. Matthew Lazzara, Antarctic Meteorological Research Center, University of Wisconsin, for the satellite images and supplementary AWS data and University of Malaya and Antarctica New Zealand for logistics support.

\section{REFERENCES}

Basset, H. A., and A. M. Ali, 2006: Diagnostics of cyclogenesis using potential vorticity. Atmósfera, 19 (4), 213-234.

Breckenridge, C. J., U. Radok, C. R. Stearns, and D. H. Bromwich, 1993: Katabatic winds along the Transantarctic Mountains. Antarctic Research Series: Antarctic Meteorology and Climatology: Studies Based on Automatic Weather Stations, D. H Bromwich and C. R. Stearns, Eds., Amer. Geophys. Union, 69-92.

Brighton, P. W. M., 1978: Strongly stratified flow past threedimensional obstacles. Quart. J. Roy. Meteor. Soc., 104, 289307, doi:10.1002/qj.49710444005.

Bromwich, D. H., 1989: Satellite analysis of Antarctic katabatic wind behavior. Bull. Amer. Meteor. Soc., 70, 738-749, doi:10.1175/1520-0477(1989)070<0738:SAOAKW >2.0.CO;2. , 1991: Mesoscale cyclogenesis over the southwestern Ross Sea linked to strong katabatic winds. Mon. Wea. Rev., 119, 1736-1752, doi:10.1175/1520-0493(1991)119<1736: MCOTSR $>2.0 . \mathrm{CO} ; 2$.

_ 1992: A satellite case-study of a katabatic surge along the Transantarctic Mountains. Int. J. Remote Sens., 13, 55-66, doi:10.1080/01431169208904025.

_ J. F. Carrasco, and C. R. Stearns, 1992: Satellite observations of katabatic-wind propagation for great distances across the
Ross Ice Shelf. Mon. Wea. Rev., 120, 1940-1949, doi:10.1175/ 1520-0493(1992)120<1940:SOOKWP > 2.0.CO;2.

_, Y. Du, and T. R. Parish, 1994: Numerical simulation of winter katabatic winds from west Antarctica crossing Siple Coast and the Ross Ice Shelf. Mon. Wea. Rev., 122, 1417-1435, doi:10.1175/1520-0493(1994)122<1417:NSOWKW>2.0.CO;2.

, J. J. Cassano, T. Klein, G. Heinemann, K. M. Hines, K. Steffen, and J. E. Box , 2001: Mesoscale modeling of katabatic winds over Greenland with the Polar MM5. Mon. Wea. Rev., 129, 2290-2309, doi:10.1175/1520-0493(2001)129<2290: MMOKWO $>2.0 . \mathrm{CO} ; 2$.

Burk, S. D., T. Haack, and R. M. Samelson, 1999: Mesoscale simulation of supercritical, subcritical, and transcritical flow along coastal topography. J. Atmos. Sci., 56, 2780-2795, doi:10.1175/ 1520-0469(1999)056<2780:MSOSSA>2.0.CO;2.

Carrasco, J. F., and D. H. Bromwich, 1994: Climatological aspects of mesoscale cyclogenesis over the Ross Sea and Ross Ice Shelf regions of Antarctica. Mon. Wea. Rev., 122, 2405-2425, doi:10.1175/1520-0493(1994)122<2405:CAOMCO>2.0.CO;2.

$\longrightarrow$, - and A. J. Monaghan, 2003: Distribution and characteristics of mesoscale cyclones in the Antarctic: Ross Sea eastward to the Weddell Sea. Mon. Wea. Rev., 131, 289-300, doi:10.1175/1520-0493(2003)131<0289:DACOMC>2.0.CO;2.

Cassano, J. J., J. E. Box, D. H. Bromwich, L. Li, and K. Steffen, 2001: Evaluation of Polar MM5 simulations of Greenland's atmospheric circulation. J. Geophys. Res., 106, 13 867-13 889, doi:10.1029/2001JD900044.

Chenoli, S. N., J. Turner, and A. A. Samah, 2012: A climatology of strong wind events at McMurdo Station, Antarctica. Int. J. Climatol., 33, 2667-2681, doi:10.1002/joc.3617.

Davis, C. A., and K. A. Emanuel, 1991: Potential vorticity diagnostics of cyclogenesis. Mon. Wea. Rev., 119, 1929-1953, doi:10.1175/1520-0493(1991)119<1929:PVDOC>2.0.CO;2.

Dee, D. P., and Coauthors, 2011: The ERA-Interim reanalysis: Configuration and performance of the data assimilation system. Quart. J. Roy. Meteor. Soc., 137, 553-597, doi:10.1002/ qj.828.

Hoskins, B. J., 1971: Atmospheric frontogenesis models: Some solutions. Quart. J. Roy. Meteor. Soc., 97, 139-153, doi:10.1002/qj.49709741202.

, M. E. McIntyre, and A. W. Robertson, 1985: On the use and significance of isentropic potential vorticity maps. Quart. J. Roy. Meteor. Soc., 111, 877-946, doi:10.1002/qj.49711147002. 
Hunt, J. C. R., and W. H. Snyder, 1980: Experiments on stably and neutrally stratified flow over a model three-dimensional hill. J. Fluid Mech., 96, 671-704, doi:10.1017/S0022112080002303.

Keliher, T. E., 1975: The occurrence of microbarograph-detected gravity waves compared with the existence of dynamically unstable wind shear layers. J. Geophys. Res., 80, 2967-2976, doi:10.1029/JC080i021p02967.

Klein, A. G., M. C. Kennicutt, G. A. Wolff, S. T. Sweet, T. Bloxom, D. A. Gielstra, and M. Cleckley, 2008: The historical development of McMurdo station, Antarctica, an environmental perspective. Polar Geogr., 31, 119-144, doi:10.1080/10889370802579856.

Klemp, J. B., and D. K. Lilly, 1975: The dynamics of wave-induced downslope winds. J. Atmos. Sci., 32, 320-339, doi:10.1175/ 1520-0469(1975)032<0320:TDOWID>2.0.CO;2.

Lazzara, M. A., G. A. Weidner, L. M. Keller, J. E. Thom, and J. J. Cassano, 2012: Antarctic Automatic Weather Station Program: 30 years of polar observation. Bull. Amer. Meteor. Soc., 93, 1519-1537, doi:10.1175/BAMS-D-11-00015.1.

Lindzen, R. S., and K.-K. Tung, 1976: Banded convective activity and ducted gravity waves. Mon. Wea. Rev., 104, 1602-1617, doi:10.1175/1520-0493(1976)104<1602:BCAADG >2.0.CO;2.

Monaghan, A. J., D. H. Bromwich, J. G. Powers, and K. W. Manning, 2005: The climate of the McMurdo, Antarctica, region as represented by one year of forecasts from the Antarctic Mesoscale Prediction System. J. Climate, 18, 1174-1189, doi:10.1175/JCLI3336.1.

O'Connor, W. P., and D. H. Bromwich, 1988: Surface airflow around Windless Bight, Ross Island, Antarctica. Quart. J. Roy. Meteor. Soc., 114, 917-938, doi:10.1002/qj.49711448205.

_ — — , and J. F. Carrasco, 1994: Cyclonically forced barrier winds along the Transantarctic Mountains near Ross Island. Mon. Wea. Rev., 122, 137-150, doi:10.1175/ 1520-0493(1994)122<0137:CFBWAT >2.0.CO;2.

Phillpot, H. R., 1991: The derivation of $500 \mathrm{hPa}$ height from automatic weather station surface observations in the Antarctic continental interior. Aust. Meteor. Mag., 39, 79-86.
Powers, J. G., 2007: Numerical prediction of an Antarctic severe wind event with the Weather Research and Forecasting (WRF) model. Mon. Wea. Rev., 135, 3134-3157, doi:10.1175/ MWR3459.1.

— A. J. Monaghan, A. M. Cayette, D. H. Bromwich, Y. H. Kuo, and K. W. Manning, 2003: Real-time mesoscale modeling over Antarctica: The Antarctic Mesoscale Prediction System. Bull. Amer. Meteor. Soc., 84, 1533-1545, doi:10.1175/ BAMS-84-11-1533.

—, K. W. Manning, D. H. Bromwich, J. J. Cassano, and A. M. Cayette, 2012: A decade of Antarctic science support through AMPS. Bull. Amer. Meteor. Soc., 93, 1699-1712, doi:10.1175/ BAMS-D-11-00186.1.

Rasmussen, E. A., and J. Turner, 2003: Polar Lows: Mesoscale Weather Systems in the Polar Regions. Cambridge University Press, 624 pp.

Seefeldt, M. W., G. J. Tripoli, and C. R. Stearns, 2003: A highresolution numerical simulation of the wind flow in the Ross Island region, Antarctica. Mon. Wea. Rev., 131, 435-458, doi:10.1175/1520-0493(2003)131<0435:AHRNSO > 2.0.CO;2.

_ J. J. Cassano, and T. R. Parish, 2007: Dominant regimes of the Ross Ice Shelf surface wind field during austral autumn 2005. J. Appl. Meteor. Climatol., 46, 1933-1955, doi:10.1175/ 2007JAMC1442.1.

Snyder, W. H., R. S. Thompson, R. E. Eskridge, R. E. Lawson, I. P. Castro, J. T. Lee, J. C. R. Hunt, and Y. Ogawa, 1985: The structure of strong stratified flow over hills: Dividing-streamline concept. J. Fluid Mech., 152, 249-288, doi:10.1017/ S0022112085000684.

Steinhoff, D. F., D. H. Bromwich, M. Lambertson, S. L. Knuth, and M. A. Lazzara, 2008: A dynamical investigation of the May 2004 McMurdo Antarctica severe wind event using AMPS. Mon. Wea. Rev., 136, 7-26, doi:10.1175/2007MWR1999.1.

Turner, J., S. N. Chenoli, A. A. Samah, G. Marshall, T. Phillips, and A. Orr, 2009: Strong wind events in the Antarctic. J. Geophys. Res., 114, D18103, doi:10.1029/2008JD011642. 